NBER WORKING PAPER SERIES

\title{
THE IMPACT OF DEUNIONIZATION ON THE GROWTH AND DISPERSION OF PRODUCTIVITY AND PAY
}

\author{
Giovanni Dosi \\ Richard B. Freeman \\ Marcelo C. Pereira \\ Andrea Roventini \\ Maria Enrica Virgillito \\ Working Paper 26634 \\ http://www.nber.org/papers/w26634
}

\author{
NATIONAL BUREAU OF ECONOMIC RESEARCH \\ 1050 Massachusetts Avenue \\ Cambridge, MA 02138 \\ January 2020
}

We thank for useful comments the participants to the Society for Computation in Economics and Finance (CEF), Milan (IT), 2018; WEHIA Conference, Tokyo (JP), 2018; International Schumpeter Society (ISS), Seoul (South Korea), 2018; EAEPE Conference, Nice (FR), 2018; AISRE Conference, Bolzano (IT), 2018; ANPEC Conference, Rio de Janeiro (BR), 2018; ICCTsinghua Conference, Beijing (CN), 2019. We gratefully acknowledge the support by the European Union's Horizon 2020 research and innovation programme under grant agreement No. 822781 GROWINPRO - Growth Welfare Innovation Productivity - and by Fundação de Amparo à Pesquisa do Estado de São Paulo (FAPESP), process No. 2015/24341-7. The views expressed herein are those of the authors and do not necessarily reflect the views of the National Bureau of Economic Research.

NBER working papers are circulated for discussion and comment purposes. They have not been peer-reviewed or been subject to the review by the NBER Board of Directors that accompanies official NBER publications.

(C) 2020 by Giovanni Dosi, Richard B. Freeman, Marcelo C. Pereira, Andrea Roventini, and Maria Enrica Virgillito. All rights reserved. Short sections of text, not to exceed two paragraphs, may be quoted without explicit permission provided that full credit, including $\odot$ notice, is given to the source. 
The Impact of Deunionization on the Growth and Dispersion of Productivity and Pay

Giovanni Dosi, Richard B. Freeman, Marcelo C. Pereira, Andrea Roventini, and Maria Enrica Virgillito

NBER Working Paper No. 26634

January 2020

JEL No. C63,E02,E24,J51

\title{
ABSTRACT
}

This paper presents an Agent-Based Model (ABM) that seeks to explain the concordance of sluggish growth of productivity and of real wages found in macro-economic statistics, and the increased dispersion of firm productivity and worker earnings found in micro level statistics in advanced economies at the turn of the 21st century. It shows that a single market process unleashed by the decline of unionization can account for both the macro and micro economic phenomena, and that deunionization can be modeled as an endogenous outcome of competition between high wage firms seeking to raise productive capacity and low productivity firms seeking to cut wages. The model highlights the antipodal competitive dynamics between a "winner-takesall economy" in which corporate strategies focused on cost reductions lead to divergence in productivity and wages and a "social market economy" in which competition rewards the accumulation of firm-level capabilities and worker skills with a more egalitarian wage structure.

\author{
Giovanni Dosi \\ EmbeDS and Institute of Economics \\ Scuola Superiore Sant'Anna \\ Piazza Martiri della Liberta', 33 \\ 56127 Pisa, Italy \\ gdosi@santannapisa.it \\ Richard B. Freeman \\ NBER \\ 1050 Massachusetts Avenue \\ Cambridge, MA 02138 \\ freeman@nber.org \\ Marcelo C. Pereira \\ University of Campinas \\ Andrea Roventini \\ EmbeDS and Institute of Economics \\ Scuola Superiore Sant'Anna \\ Piazza Martiri della Liberta', 33 \\ 56127 Pisa, Italy \\ and OFCE, Sciences Po, \\ Sophia-Antipolis, France \\ andrea.roventini@santannapisa.it \\ Maria Enrica Virgillito \\ EmbeDS and Institute of Economics \\ Scuola Superiore Sant'Anna \\ Pisa (Italy) \\ m.virgillito@santannapisa.it \\ Barao Geraldo, Campinas \\ São Paulo, 13083-970 \\ Brazil \\ mcper@unicamp.br
}




\section{Introduction}

In the first two decades of the $21^{\text {st }}$ century advanced capitalist economies experienced a striking set of changes in macro-economic, micro-economic and institutional patterns that merit explanation. At the macro level, productivity growth slackened even as R\&D spending increased, and real wage growth decoupled from the productivity growth to increase at far lower rates. ${ }^{1}$ At the micro level, inequality increased among firms in productivity and in the average earnings paid to workers. Over the same period, the institutional structure of labor markets changed, with the proportion of workers covered by unions shrinking nearly everywhere. ${ }^{2}$ Empirical studies document these patterns in enough data sets and countries to establish them as stylized facts for theory and models of how capitalism operates in a modern economy.

What explains the concordance of sluggish macro-economic performance and divergence in micro-economic firm outcomes? What connection, if any, exists between those patterns and declining unionization?

This paper presents an Agent Based Model (ABM) of the dynamics of productivity growth and wage determination in labor markets with and without unions that offers a unified explanation for all above patterns. The model simulates an economic world in which firms endowed with heterogeneous productive capacity compete under two apposite labor relation systems: one that we label as "non-union" in which firms unilaterally set wages and hire and fire workers and one that we label as "union" in which firms pay the same collectively determined wage for similar workers, and follow a collective agreement in hiring and firing. The non-union system pressures low-productivity firms to cut wages to survive. The union system pressures firms to invest in productivity-enhancing activities to survive. The differential pressure makes the mode of wage setting a selection mechanism among firms with heterogeneous strategies of squeezing worker pay vs enhancing worker and firm competence. The model accounts for the deunionization, sluggish growth of productivity and real wages and increased dispersion of firm pay and productivity of advanced countries in terms of micro market behaviors rather than as independent phenomena following their own dynamics.

ABMs are well-suited to analyze the concordance of micro, macro, and institutional developments. They differ from stochastic general equilibrium models by being open-ended simulations driven by heterogeneous agents who follow simple bounded rationality rules of behavior in disequilibrium situations, rather than being closed-form solutions derived from linearization around equilibrium conditions. The rules govern the internal growth or decline of firms over time and the entry and exit of firms that together change micro productivity and pay, and aggregates to macro and institutional outcomes.

\footnotetext{
${ }^{1}$ On the aggregate facts, Syverson (2017) shows that US labor productivity growth fell from $2.8 \%$ in 1995 2004 to $1.3 \%$ in 2005-2015 and that 29 out of the 30 advanced countries had similar declines; Hutchinson and Persyn (2012) and Karabarbounis and Neiman (2013) document the falling labor share of income in developed countries; Schwellnus et al. (2017) show that the fall was accompanied by an increasing ratio of the mean wage to the median wage income that reflects a widening distribution of wage income. On the micro facts, Dunne et al. (2004) estimate a sizeable firm contribution to wage dispersion, Barth et al. (2016) show that increased inter-establishment wage dispersion contributes roughly twice as much to the growth of wage dispersion in the US as the increase in intra-establishment inequality. Berlingieri et al. (2017) document rising dispersion in wages and productivity across 16 OECD countries from the mid-1990s to 2012. While the estimated magnitudes of these effects vary, we know of no empirical evidence that contravenes the stylized patterns.

${ }^{2}$ Farber et al. (2018) for US, Ebbinghaus and Visser (1999) for EU.
} 
A recurrent concern with ABMs is that analysts who focus on explaining a few stylized facts may "overfit" the model with many behavioral rules designed for those facts but which would not hold generally. Building our analysis on the "Schumpeter meeting Keynes" $(\mathrm{K}+\mathrm{S})$ family of models that robustly accounts for a large ensemble of stylized facts at micro- and macro-levels (see references to Table 2), we avoid this problem. We further conduct robustness tests of the simulations to a range of different values of parameters.

\section{Dispersion of productivity and wages and the dynamics of de- unionisation}

Our agent-based modeling situates micro behavior in market settings where competition imposes evolutionary pressure on agents. The main agents are firms whose characteristics and behavior give them differing market rewards. Those with higher rewards prosper and expand in the market while those with lower rewards see their share of market outcomes shrink. The firms are heterogeneous in their productivity but have limited ways to learn and adjust behavior.

The assumption of firm heterogeneity is predicated on evidence that documents the overweening importance of heterogeneity in productivity and wages among firms and the establishments where they conduct business. The data show:

- Wide dispersion among firms in productivity and average pay in a given period (Dunne et al., 2004) and in changes in productivity and pay even among demographically identical workers in narrowly defined industries and occupations (Barth et al., 2016).

- Within firm growth of productivity having a bigger impact than reallocation of workers from low- to high-productivity firms on aggregate productivity growth (Dosi et al., 2015). ${ }^{3}$

- Lower dispersion of productivity in economies with compressed wage structures, as the compressed wage structure pushes low productivity companies out of the market (Barth et al., 2014). ${ }^{4}$

- Lower dispersion of pay within and among unionized compared to non-union establishments for workers with similar measured skills and for the same workers who change employment over time (Freeman, 1984).

- An increasing share of "zombie firms" in the US from 2003 to 2013 - firms unable to pay outstanding interest but failing to exit the market (McGowan et al., 2017). This failure in market "cleansing" contributes to sluggish aggregate productivity growth.

Taken together the failure of market forces to compress the widening distribution of wages towards central levels even in the US, where union/institutional constraints on market forces are weakest, suggests the need for a model of labor market adjustment that goes beyond the assumption that the institution-less non-union market determines a single market-clearing wage in the long run, if not in the short or intermediate run.

Our ABM model links the macro and micro facts to institutional developments by sim-

\footnotetext{
${ }^{3}$ The contribution of reallocation seems to further weaken post the Great Recession (Foster et al., 2016), with the rate of entry of new firms falling while exit rates holding steady (Decker et al., 2016).

${ }^{4}$ Earlier work by Hibbs Jr and Locking (2000) show that lower within-plant wage standard deviation is associated with higher productivity levels, with a shift of labour from low- to high-productivity firms.
} 
ulating the interaction of union and non-union wage-setting systems with heterogeneity in the distribution of productivity among firms. Figure 1 shows the essence of the model. ${ }^{5}$ The $x$ axis in each panel ranks firms from the most to the least efficient while the $y$ axis shows how efficiency translates into costs and thus the likely survivability of firms. Panel $A$ represents an industry with a union-bargained wage that applies to all firms so that the ranking of firms from the most productive (firm 1) to the least productive (firm $n$ ) ranks them inversely by unit costs. With all firms paying the same wage to equally skilled workers, the more productive firms have lower costs. If the firms compete in a market with a single price, the dynamics favors them and they expand while less efficient firms shrink. The single bargained wage prevents firms from squeezing wages and thus pressures them to compete on productivity and thus for selection on productivity. In panel $A$ union firms 1 through $n-2$ remain in the market while union firms $n-1$ and $n$ are driven out, which truncates the distribution of productivity.

Panel $B$ depicts an industry in the opposite "non-union" situation where firms pay workers a wage indexed on firm-specific productivity. In this case all firms have the same unit costs of production and survive irrespective of their efficiency. Competition does not favor firms 1,2,3 with higher relative productivity as their wages are commensurately higher relative to their productivity. If productivity falls for any reason in a firm, the firm reduces pay to survive, which allows the inefficient firms $n-2$ to $n$ to stay in business. Dispersion of productivity is bound only by low productivity workers with reservation wages above the wage that would justify their low productivity.

Panel $C$ analyzes competition between unionized firms that pay a single wage dependent on the average productivity of the unionized group and non-unionized firms whose wages depend only on their firm's productivity. As non-union firms enter, their production reduces the price of the good and pressures the least efficient union firms. In this case competition can exert a negative impact upon the dynamics of mean productivity as union firms with below union-group productivity but higher productivity than non-union firms go out of business while non-union firms with low productivity and low wages survive.

Noting the tendency for labor unions to grow rapidly and decline slowly, Freeman (1997) proposed a spurt model of unionization, which entails a phase transition triggered after some tipping point that leads many workers and firms to unionize in a sudden sharp increase. This is followed by competitive exit and entry forces that can favor non-union firms and gradual reduce union density. ${ }^{6}$ Interpreting unionization as stemming from workers and firms, Bryson et al. (2017) argue that deunionization is driven largely by new cohorts of workers/firms who do not unionize rather than by previously unionized workers / firms abandoning the institution. New firms experience a "never-member" effect as workers with no union experience are unlikely to demand this good/service against a management that prefers to operate non-union. In fact, young workers express greater desire for unions than older workers (Bryson et al., 2005) but are less likely to be able to

\footnotetext{
${ }^{5}$ This representation draws on Salter (1960) analysis of the productivities of different vintages of equipment.

${ }^{6}$ In this analysis, governments that enact laws favorable to unions, such as the Wagner Act in US, the Blum government in France, or the PC 1003 in Canada are responding to worker pressures in the spurt. The laws are not an exogenous determinant of unionism from the top but a pathway created to "tame" worker unrest.
} 
accomplish that desire within the organization and thus less willing to try to overcome management's strategy to remain non-union. ${ }^{7}$

We begin our simulation model with a completely unionized labor market. Then nonunion firms enter. Unionized and non-unionized firms compete in the product market in terms of relative prices, product quality and quantity (excess or unfilled demand), which determine the average dispersion of productivity and wages. If the share of employment/output in non-union companies increases, the mean level of productivity growth declines while the standard deviation of productivity among firms increases. Competition shifts from improving productivity to reducing wages and cost. Firms whose comparative advantage lies in cutting pay gain at the expense of those whose advantage lies in high productivity. Cost competition induces a deflationary spiral, and reduces product quality.

But a simple strategy of reducing wages may not succeed in driving out higher wage/ more productive firms. To the extent that lower wages reduce the quality of production or rate of improvement of productivity, the new low wage competitors may fail to survive over the long run even if they increase their share of production in the short run. We use the model to explore the nexus between deunionization and the stylized productivity facts and the factors that determine whether a given labor market will shift its wage-setting system.

\section{The model}

Figure 2 gives the bare-bones structure of the model. It extends Dosi et al. $(2017,2018)$ variant of the basic $\mathrm{K}+\mathrm{S}$ artificial economy (Dosi et al., 2010) that included endogenous worker skill accumulation and variable number of firms in a general disequilibrium, stock-andflow consistent, agent-based model, populated by heterogeneous workers/consumers, capital-good firms, consumption-good firms, and banks, plus the central bank and government. $^{8}$ Agent behavior follows bounded-rational rules. To apply the model to our problem we add two differentiated mechanisms of job hiring and firing, search process, and wage setting to characterize the type of firm. ${ }^{9}$

The model highlights the importance of increasing knowledge in the growth of productivity by dividing firms between those that produce capital-goods and those that produce consumption goods. The capital good firms invest in R\&D and produce heterogeneous goods/services/knowledge that raise the productivity of the consumption-good firms. This is the locus of endogenous innovation, characterized by imperfect information and Schumpeterian competition driven by technological change. Given the increased proportion of investment in software and in information, communication, and technology equipment, we view this sector as extending beyond traditional producers of machine tools/equipment to include those developing new software and information, technology, and communication goods and services.

Since creating knowledge depends critically on human activity, we make labor the only factor of production in the capital-goods producing sector. These firms report the

\footnotetext{
${ }^{7}$ For evidence that this may be changing among "millenials" see https://www.rewire.org/work/ younger-workers-labor-unions/.

${ }^{8}$ Subscript $t$ stands for (discrete) time $t=1,2, \ldots, T$. Agent-specific variables are denoted by subscript $\ell$, in case of workers, $i$, for capital-good firms, $j$, for consumption-good firms, and $k$, for banks.

${ }^{9}$ The code and a user-friendly interface are accessible at https://github.com/marcov64/ lsd.
} 
price and productivity of their machines and services to current customers and a subset of potential new ones, and invest a fraction of past revenues in R\&D aimed at improving their products. They set prices at a fixed mark-up over labor costs. In a typical model run, capital-good firm workers represent less than $10 \%$ of the employed labor force, so we focus on labor patterns in the consumption-good sector.

Consumption-good firms combine vintages of capital bought from capital-goods firms with labor to produce a single, quality-differentiated good for consumers under constant returns to scale. Desired production is determined by adaptive demand expectations. Given inventories, if the current capital stock cannot produce the desired output, firms order new machines to expand capacity, funded by retained past profits or, up to a limit, bank loans. They replace old machines according to a payback-period rule. Firms choose the capital-good supplier based on the price and productivity of machines. As new machines embed state-of-the-art technologies, the productivity of consumption-good firms increases over time. Consumption-good firms set prices by a variable mark-up on labor production costs to balance profit margins and market shares, raising (lowering) mark-ups and prices when market shares expand (decline). Due to imperfect information their consumers switch gradually to the most competitive producer so that market shares evolve according to a (quasi) replicator dynamics as more competitive firms expand, while less competitive firms shrink or close down.

Exit and entry of firms is endogenous in both sectors. Firms exit when market shares get close to zero or go bankrupt when net assets turn negative. Conversely, firms enter the market through a stochastic process that depends on the number of incumbents and financial conditions. Entry is easier when the sectoral liquidity-to-debt ratio is high. Banks take deposits and provide interest-paying loans to finance firms' production and investment plans. They allocate credit to firms seeking credit according to a loan to value ratio rule. The supply of credit is elastic.

The labor market is modeled as a decentralized search-and-hire process between workers and firms. Workers search for jobs at a random subset of employers. The unemployed submit job applications to firms. A proportion of employed workers apply for better positions. Larger firms have a proportionally higher probability of receiving job applications, which are organized in firm-specific application queues. Capital-good firms hire workers according to their demands. Consumption-good firms hire workers depending on adaptive demand expectations; while for simplicity, banks, the central bank and the government have no workers. The aggregate supply of labour is fixed and available to be hired in any period.

The labour market is also characterized by imperfect highly localized information. Firms observe workers' skills and wage requests on their own queues, while workers are aware only of the wage offers from firms where they applied for a job. Firms decide whether to hire, fire or keep the current labor force. Each hiring firm makes a unique wage offer to job applicants, based on economy-wide productivity in the case of union firms and on the received applications in non-union ones. Workers select the best wage offer from firms to which they submitted applications, with employed workers quitting the current job if they receive a better offer.

We treat one round of interactions between workers and firms per period. The overall demand for labor depends on the aggregate demand of the economy, which creates the possibility that the labor market does not clear even absent firing or hiring transaction 
costs. Firms may fail to fill all open positions, and workers may not find a job even when there are still unfilled positions. Systematic discrepancies between vacancies and involuntary unemployed are likely to be the rule rather than the exception in the aggregate.

Workers spend their income on the consumption good. ${ }^{10}$ If the supply of the consumer good falls short of demand, excess demand is saved in banks for future consumption. The central bank sets the reserves from the banks and bails out failing banks. The government taxes firm and bank profits, pays unemployment benefits, imposes a minimum wage, absorbs profits and losses from the central bank and keeps a non-explosive public debt trajectory in the long run.

Two other distinctive features of our model deserve attention. First, firms decide how much to produce extrapolating on their past sales (Dosi et al., 2017). Past equipment is bygone and remains part of firms' resources if the firm does not scrap it. Conversely expansionary investment depends on the fixed coefficient associated with a new machine (and software) offered by the machine-producing sector based on a pay-back rule, which has little to do with elasticity of substitution (Dosi et al., 2001). This treatment simplified the demand for labor from the notion of choice along a production function.

Second, we do not model "strategic" game theoretic interactions among firms. Instead, we treat organizational traits of behavior as sticky, irrespective of market signals (Dosi et al., 2001). That is Toyota does not become Foxcom under any circumstance and vice versa. In our model this is reflected by the absence of any firm-level switching rule driven by relative performance. Instead, given their organizational types, firms are selected by competitive forces.

Appendix A contains the details of the model.

\subsection{Competition between unionised and non-unionised firms}

Table 1 contrasts the wage-setting and other features of union firms and non-union firms. Unionized firms pay the same wages to all workers with the same skills and change wages as aggregate and market productivity change. They fire employees only when profits become negative. Their workers seek alternative jobs less frequently than non-union workers, consistent with the exit-voice trade-off in the labor market (Freeman, 1980). In hiring and firing, firms try to keep the more skilled workers. Conversely, non-unionised firms set wages according to worker skills and labor market conditions. Wages are set by an asymmetric negotiation process where firms have the last say over workers. There are no hiring/firing protections and unemployed workers adjust downward their "satisficing" wages.

Employed workers search for better paid jobs and firms fire excess workforce according to planned production. Hiring and firing of workers is based on the skills to (individual) wage ratio or just the latter, according to the scenario. The market share of unionised firms is $f_{t}^{u} \in[0,1]$ while that of non-unionised firms is $f_{t}^{n} \in[0,1]$.

To focus on the decline in unionization, we assume that non-union firms enter and compete with union incumbent firms in an evolutionary process. From $t=100$, the probability of an entrant being non-union is fixed at 50\%. The time window $(100 \leq t<200)$ allows non-union entrants to grow and achieve some joint market share. At the end of this

\footnotetext{
${ }^{10}$ The macroeconomic results hold as long as the propensity to consume out of wages is higher than out of profits. Volatility of spending is lowest for consumption, then for GDP, and highest for investment.
} 
period the likelihood of union or non-union firms entering the consumer-good market is proportionate to their relative populations $f_{t-1}^{u}$ and $f_{t-1}^{n}$.

In the consumer-good sector, firms compete according to their relative cost competitiveness. Firm $j$ market share evolves following a replicator dynamics:

$$
f_{j, t}=f_{j, t-1}\left(1+\chi \frac{E_{j, t}-\bar{E}_{t}}{\bar{E}_{t}}\right), \quad \bar{E}_{t}=\frac{1}{F_{t}^{2}} \sum_{j} E_{j, t} f_{j, t-1},
$$

where $\chi \in \mathbb{R}_{+}$is a parameter, $F_{t}^{2}$ the current number of firms in the consumer-good market, $\bar{E}_{t}$ the average competitiveness, and the firm relative competitiveness $E_{j, t}$ is defined by the individual normalized price $p_{j, t}^{\prime}$, unfilled demand $l_{j, t}^{\prime}$ and product quality $q_{j, t}^{\prime}$, with parameters $\left(\omega_{1}, \omega_{2}, \omega_{3}\right) \in \mathbb{R}_{+}^{3}$ :

$$
E_{j, t}=-\omega_{1} p_{j, t-1}^{\prime}-\omega_{2} l_{j, t-1}^{\prime}-\omega_{3} q_{j, t-1}^{\prime}
$$

Firms set consumption-good prices by a variable mark-up $\mu_{j, t}$ on average unit cost $c_{j, t}$ :

$$
p_{j, t}=\left(1+\mu_{j, t}\right) c_{j, t} .
$$

Firms' mark-up rule is driven by the evolution of individual market shares with parameter $v \in \mathbb{R}_{+}$:

$$
\mu_{j, t}=\mu_{j, t-1}\left(1+v \frac{f_{j, t-1}-f_{j, t-2}}{f_{j, t-2}}\right),
$$

Unfilled demand $l_{j, t}$ is the difference between actual demand $D_{j, t}$ firm $j$ gets and its effective production $Q_{j, t}$ plus existing inventories $N_{j, t}$ from past periods, if any:

$$
l_{j, t}=\max \left[D_{j, t}-\left(Q_{j, t}+N_{j, t}\right), 0\right] .
$$

The quality of consumer-good produced by firm $j$ is determined by the average (log) skill level of its workers. This captures the notion that firm-specific accumulated skills are more complementary to incremental product innovation.

$$
q_{j, t}=\frac{1}{L_{j, t-1}} \sum_{\ell \in\left\{L_{j, t-1}\right\}} \log \left[s_{\ell, t-1}\right],
$$

The skill of employed workers improves over time while unemployed workers lose skills:

$$
s_{\ell, t}=\left\{\begin{array}{cl}
\left(1+\tau_{T}\right) s_{\ell, t-1} & \text { if employed in } t-1 \\
\frac{1}{1+\tau_{U}} s_{\ell, t-1} & \text { if unemployed in } t-1,
\end{array}\right.
$$

where $\left(\tau_{T}, \tau_{U}\right) \in \mathbb{R}_{+}^{2}$ are parameters governing the learning rate while the worker is employed or unemployed. A newly hired worker immediately acquires the minimum skill level present in the firm - the incumbent worker with the lowest skills -, if above her present level. Workers have a fixed working life, retiring at a specified point, at which they are replaced in the labour market by young workers with skills at the current minimum level among employed workers. At the beginning of each simulation, initial working ages are randomly drawn in the range $1,2, \ldots, T_{r}$ ( $T_{r}$ is a parameter) and start from the same skill level. 
Worker $\ell$ current skills $s_{\ell, t}$ define her individual (potential) productivity:

$$
A_{\ell, t}=\frac{s_{\ell, t}}{\bar{s}_{t}} A_{i}^{\tau},
$$

being $\bar{s}_{t}$ the average overall skill level of the economy, and $A_{i}^{\tau}$ the standard productivity of the specific machinery vintage the worker operates. Thus, the worker's normalized skill represents her productivity relative to that expected for the machine vintage. This makes firm-level effective productivity an emergent property resulting from the supplierdriven introduction of new vintages, evolution of workers' skills, and the demand decisions which guide capital accumulation and vintage mix of machines:

$$
A_{j, t}=\frac{1}{L_{j, t-1}} \sum_{\ell \in\left\{L_{j, t-1}\right\}} A_{\ell, t},
$$

where $L_{j, t}$ is the number of workers at firm $j$, and $\left\{L_{j, t}\right\}$, the size of this set. So, if the mean wage paid by firm $j$ is $w_{j, t}$, its average unit cost is given by:

$$
c_{j, t}=\frac{w_{j, t}}{A_{j, t}} .
$$

Finally, we allow for other pay setting institutions through a profit-sharing mechanism which allows firms with above-average profits distribute bonuses. For simplicity, bonuses are equal for all workers in the firm. Thus, the total bonuses by firm are:

$$
B_{j, t}=\psi_{6}(1-t r) \Pi_{j, t-1},
$$

being $\psi_{6} \in[0,1]$ a sharing parameter, $\operatorname{tr} \in[0,1]$ the tax rate parameter, and $\Pi_{j, t}$ the firm gross profit. Therefore, the total income of worker $\ell$ working for firm $j$ in period $t$ is $w_{\ell, t}+B_{j, t} / L_{j, t}$.

Appendix A describes the remaining behavioural rules characterizing agents. Appendix $C$ gives model's parameters, initial conditions and stock-flow matrix. In each simulation period the following events take place:

\section{INITIATION OF CHANGES}

1. Workers (employed and unemployed) update their skills;

2. Machines ordered in the previous period (if any) are delivered;

3. Capital-good firms perform R\&D and signal their machines to consumption-good firms;

4. Consumption-good firms determine their desired production, investment and workforce;

\section{RESPONSES TO CHANGES}

5. Firms allocate cash-flows and (if needed) borrow from banks to operate and invest;

6. Firms send/receive machine-tool orders for the next period (if applicable);

7. Job-seeking workers send job applications to firms;

8. Wages are set (collective indexation or individual negotiation) and job vacancies are partly or totally filled;

9. Firms pay wages/bonuses and government pays unemployment benefits;

\section{MARKET OUTCOMES}


10. Consumption-good market opens and market shares are allocated according to the relative competitiveness of firms;

11. Firms and banks compute their profits, pay taxes and repay (part of) their debt;

12. Exit takes place, near-zero share and bankrupt firms leave the market;

13. Prospective entrants decide to enter according to market conditions;

14. Aggregate variables are computed and the cycle restarts.

\section{Robustness and interpretative power}

As noted, our model builds on earlier variants of the $\mathrm{K}+\mathrm{S}$ model that generate endogenous growth and business cycles, and fit stylized facts beyond those on which we focus. The top panel of Table 2 lists the stylized facts that the model fits at both the macro and the micro-economic levels while the bottom panel shows the stylized facts fit by the laborenhanced version of the model, which explicitly accounts for decentralized firm-worker interactions.

Our model adds union and non-union wage setting and competition as described in Table 1. The simulations produce two key scenarios: (1) successful non-union firms invasion of the previously all union market; and (2) the setting where the union firms overcome the challenge of new competitors maintaining market dominance.

The difference between the set-ups depends critically on the worker hiring and firing rules of entering non-union firms. In the first scenario, non-union firms consider both worker wage and skills when hiring or firing, which enables them to gain advantage over union firms. In the second scenario, non-union firms just evaluate wages when hiring/firing and fail to overturn the market by being too "lean and mean". The evidence of deunionization makes the first scenario the realistic one. Indeed, while we have not modeled a union spurt, being too lean and mean could potentially lead to such an event.

The two scenarios yield similar qualitative results for outcomes that were not "built into" the model and that fit stylized facts for labor markets and versions of $\mathrm{K}+\mathrm{S}$ models which did not build in unionism. ${ }^{11}$

Figure 3(a) shows that in both scenarios the firm size-rank distributions in the consumer-good sector (where we apply the analysis) is right skewed with a heavier tail than a fitted lognormal distribution. Figure 3(b) shows a dynamics reasonably consistent with a Gibrat multiplicative process where growth is independent from initial conditions, ${ }^{12}$ while Figure 3(c) shows a Laplace process which relaxes the strong form of the Gibrat's law with i.i.d. growth rates, fitting both scenarios better. While the parameters on the higher moments differ between the two, both robustly display heavy-tailed properties. Figure 3(d) depicts the scaling of (log) standard deviation of the growth rate with respect to firm size. Finally, we also find that productivity is positively autocorrelated in time. ${ }^{13}$ All these results are in line with the empirical evidence. ${ }^{14}$

\footnotetext{
${ }^{11}$ All figures (except Figure 8) and tables below are from 100 Monte Carlo (MC) runs of the model. MC runs are required because of the stochastic components in the model. One hundred runs yield narrow confidence intervals for the mean results.

${ }^{12}$ Figures 3(b) and 3(d) report results for the no-invasion scenario however the patterns are qualitatively similar for both

${ }^{13} \mathrm{AR}$ parameters are approximately equal to 0.9 in both scenarios.

${ }^{14}$ For discussions on the stylized facts on the dynamics of industries, see Dosi et al. (2017); Bottazzi and Secchi (2006); Calvino et al. (2018).
} 
The value added of differentiating non-union and union firms is that it gives us a way to analyze the conditions under which non-union firms come to dominate the market with firm-level pay-setting and the impact of that dominance on dispersion of productivity and wages and on productivity growth. In the deunionization scenario, non-union firms consider both worker wage and skills when hiring or firing, which enables them to gain advantage over union firms. In the scenario where unions survive, non-union firms evaluate wages but do not adjust for worker skills when hiring/firing, failing to dominate the union firms by being too "lean and mean".

Figure 4 shows the "organizational ecologies" in the two scenarios. Panel 4(a) gives the outcome in which the non-union firms dominate, Panel 4(b) shows cases in which the invasion fails due to the (stochastic) competition process between the two types of firms, and the path-dependence in the model. The light grey area represents the maximum and the minimum realizations of the model while the dark grey gives the $95 \%$ confidence interval. What explains the differences between the two scenarios? By changing their hiring/firing strategy to hiring lower wage workers and firing high wage workers without taking account of heterogeneity in worker productivity the non-union firms fail to take over the market.

What happens to wages? Figure 5(a) presents the distribution of firm average wages. It is far less dispersed in the scenario where the majority of firms remain union. This is also true for the distributional width of wage growth rate in Figure 5(b). When union firms prevail, a much more egalitarian wage dynamics pattern emerges. The distributional difference is huge - more than twice wider in log terms in the case the non-union firms invasion succeeds, which in turn produces a far more skewed income distribution and larger Gini coefficient in the economy as a whole, as shown in Table 3.

What happens to productivity growth? Figure 6(a) compares productivity growth in the two scenarios. The successful invasion of non-union firms reduces overall productivity growth median by 0.20 percentage points per period - a significant slowdown caused by deunionization due to the entering non-union firms having lower productivity than the union firms at the lower tail of the union distribution whose productivity advantage does not compensate for the union wage premium. Figure 6(b) shows a further result: a fall in the quality of goods due to the workers shorter tenure and skills, which maps into lower quality products. In the non-union scenario, non-union firms prevail independently of product quality as their cheaper and less skilled labor compensate for their inferior quality. The invasion, together with the productivity slowdown, entails also a deflationary tendency in long-run price consumer index (Figure 6(c)). Finally, Figure 6(d) shows that the concentration is substantially higher in the invasion case with fewer firms appropriating a higher fraction of the market. This is consistent with a more heterogeneous sales growth dynamics when invasion succeeds, with fewer firms experiencing substantial profits and more facing losses.

Figure 7 examines the timing of the deceleration and increased dispersion of productivity growth in some detail. Panel 7(a) shows that the rates of growth of productivity of the non-union firms is lower when they come to dominate the market than productivity growth of the union firms in the no-invasion case. It also reveals that the invasion scenario is not symmetric. Whereas a small niche of union firms precariously survive in the successful non-union invasion, in the latter scenario the non-union invaders eventually all die. Panel Figure 7(b) shows that the standard deviations of productivity explode in 
the transient period, irrespective of the long-term outcomes, and in a successful invasion settles at a level higher than in the pre-invasion period.

What happens to other outcomes? Table 3 summarizes the performance of the two scenarios in the model in terms of average values for all substantial outcomes, where for simplicity we take the invasion configuration as the baseline. All the scenario means (from 100 Monte Carlo runs) are statistically different at $1 \%$ significance or less. Long-run GDP growth is $17.6 \%$ higher in the non-invasion case, indicating the relevance of unions to the potential output. This gap is mostly explained by the gain of $13.8 \%$ in the productivity growth when unionised firms prevail. In terms of distribution, persistent unionization is associated with a more equal distribution of wages, a smaller discretionary part of wages themselves (via bonuses) and a lower industry concentration.

Figure B.1 in the Appendix B shows the temporal dynamics in the performance of union and non-union firms for selected outcomes. We further probed the model with a global sensitivity analysis (SA) to see how different parametrizations affect the qualitative results. Appendix $C$ shows that the model is robust to different parametrizations. The parameters which influence collective outcomes have only marginal effects on the latter, which makes the entire model sufficently stable. ${ }^{15}$

\section{Shift-and-share decomposition of productivity growth}

To see if within-firm adjustments due to firm-specific learning or reallocation of labor contributed most to the deceleration of productivity growth, we decomposed simulated productivity growth in the consumption-good sector into its shift and share components per Foster et al. (2001):

$$
\Delta \log A_{t}=\underbrace{\overbrace{\sum_{j} f_{j, t-h} \Delta \log A_{j, t}}^{\text {WITHIN }}+\overbrace{\sum_{j} \Delta f_{j, t}\left(\log A_{j, t-h}-\log A_{t-h}\right)}^{\text {BETWEEN }}+\overbrace{\sum_{j} \Delta \log A_{j, t} \Delta f_{j, t}}^{C R O S S}}_{\text {INCUMBENTS }}
$$

$$
+\overbrace{\sum_{j} f_{j, t}\left(\log A_{j, t}-\log A_{t-h}\right)}^{E N T R Y}-\overbrace{\sum_{j} f_{j, t-h}\left(\log A_{j, t-h}-\log A_{t-h}\right)}^{E X I T}
$$

where $f_{j, t}$ is the employment share and $A_{j, t}$ is the labour productivity of firm $j$, and $\log A_{t}$ is the sectoral weighted average (log) productivity in period $t$. The first term is the within-firm component of productivity growth measured by the firm level productivity change weighted by firm's share of labor. The second term is the between-firm component measured by firm labor share weighted by the firm's relative productivity. The third term captures the covariance of the firms' productivities and labour allocations. The last two terms measure the proportional contribution of the entry and exit of firms in the market. All terms are normalized with the industry average productivity. The decomposition is computed over a rolling window of fixed length (set at 8 periods), which adds an extra term for the unexplained difference between the total and the sum of the decomposition components.

\footnotetext{
${ }^{15}$ This addresses the criticism of ABM's concerning the role of "lucky" parameter choices in results. Fagiolo et al. (2017) discuss validation of agent-based models. Dosi et al. (2018) detail the SA methodology.
} 
Table 4 represents the overall productivity growth for 200 periods post the initial influx of non-union firms. Panel B.2(a) of Appendix B presents the decomposition results for the final part of the transient period [170;200]. Panel B.2(b) gives results for union firms and Panel B.2(c) gives the results for non-union firms. The analysis of this period highlights the drivers of productivity dynamics when a significant number of both firm types still coexist. The decomposition shows that:

1. The within component reflecting the accumulation of firm capabilities and worker skills accounts for the largest part of productivity growth, though the between component has a non-negligible impact on productivity growth as well.

2. Entry and exit plays a small net role in the long run. The exit of unionized firms reduces productivity growth as deunionization proceeds.

3. Union firms in the no-invasion scenario exhibit substantially higher productivity growth compared to non-union firms in the invasion case. This fits with the slowdown of productivity growth from the post World War II "golden age of capitalism" to the 1970s/1980s as compared to the 2010s period that accompanies deunionization.

4. The market selection intensity, measured by the difference between the total productivity growth and the within component, is higher in the no-invasion scenario.

Following Bagger et al. (2014), we regress the average real wage $r w_{j}$ paid by firm $j$ on firm productivity $A_{j}$ to analyse the relation between wages and productivity in the period just after the transition to the largely non-union world $(t=200)$ :

$$
\log r w_{j}=\alpha+\beta \log A_{j}+\epsilon_{j}
$$

where $\epsilon_{j}$ is the error term. We fit the equation for each Monte Carlo (MC) realization in both scenarios using OLS. The purpose is to evaluate the degree according to which more productive are also higher-wage firms. Typical outcomes are depicted in Figure 8 for a representative simulation run. For comparison, a non-parametric regression is also estimated using an Epanechnikov kernel. Table 5 gives the regression results for the full set of $100 \mathrm{MC}$ runs. The estimated slope parameters are typically significant at the $1 \%$ level for most runs and the mean $R^{2}$ are quite high. ${ }^{16}$ The improvement associated to nonparametric estimation suggests a mildly non-linear relation between the two variables.

The smaller firm-level elasticities of wages to productivities in the non-invasion scenario than in the invasion scenario means that wages growing in relatively uniform manners in the union regime favor selection among firms driven by relative efficiencies per Figure 1.A above. Conversely, non-union firm wages track much more closely firm-level productivities, which tend to shelter less efficient firms from competitive selection (Figures 1.B, 1.C). Figure 9 presents the chain of feedback mechanisms occurring throughout the process.

\section{Conclusions}

The Agent-Based Model in this study endogenously accounts for the deunionization found in most advanced economies in the past few decades, and shows that it is intrinsically related to the sluggish growth and widened dispersion among firms in productivity

\footnotetext{
${ }^{16}$ The small MC standard errors indicate that most model realizations produce results quite close to the averages.
} 
and wages. Starting from a fully unionised economy in which firms pay a collectively determined wage related to market productivity and face strong hiring/firing restrictions, we traced out the impacts on economic outcomes of an invasion of non-union firms that paid workers wages proportional to their individual productivity.

The outcome which fits observed phenomena is when the non-union invasion triumphs. This produces an economy with lower GDP, skills and productivity growth, higher dispersion of wages and productivity among firms and a lower effectiveness of market competition in weeding out less efficient firms than when unionized firms maintain their market presence. While innovative opportunities are the same in the non-union world and in the scenario where union firms survive the invasion, absence of a collective mechanism of wage formation in the non-union setting dampens the power of efficiencydriven market selection of firms and allows the opposite selection process to emerge, where the low wages paid by the least productive/lowest skill firms drive out the most productive ones.

Viewed broadly, our results suggest that an economy in which collective wage-setting narrows the distribution of wages and institutional rules guide hiring/firing will outperform an economy in which low productivity firms can compete through low wages. In terms of growth and dispersion of pay and productivity there is no equity-efficiency tradeoff. Rather, the simulated model offers an explanation of the concordance of deunionization, rising dispersion of firm outcomes, and sluggish productivity growth over the past several decades. The market forces that we simulated were unable to control inequality and stagnation much as they (and potentially other market forces outside our simulations) have failed to do so in the real world. The Invisible Hand seemingly needs some strong and visible assistance in achieving equitable and efficient outcomes.

\section{References}

Bagger, J., B. J. Christensen, and D. T. Mortensen (2014). Wage and labor productivity dispersion: The roles of total factor productivity, labor quality, capital intensity, and rent sharing. In 2014 Meeting Papers.

Barth, E., A. Bryson, J. C. Davis, and R. Freeman (2016). It's where you work: Increases in the dispersion of earnings across establishments and individuals in the United States. Journal of Labor Economics 34(S2), S67-S97.

Barth, E., K. O. Moene, and F. Willumsen (2014). The Scandinavian model—an interpretation. Journal of Public Economics 117, 60-72.

Berlingieri, G., P. Blanchenay, and C. Criscuolo (2017). The great divergence (s). Technical report, OECD Science, Technology and Industry Policy Papers, No. 39, OECD Publishing, Paris.

Bottazzi, G. and A. Secchi (2006). Explaining the distribution of firm growth rates. The RAND Journal of Economics 37(2), 235-256.

Bryson, A., R. Freeman, R. Gomez, and P. Willman (2017). The twin track model of employee voice: An anglo-american perspective on union decline and the rise of alternative forms of voice. Technical report, IZA Discussion Paper No. 11223. 
Bryson, A., R. Gomez, M. Gunderson, and N. Meltz (2005). Youth-adult differences in the demand for unionization: Are american, british, and canadian workers all that different? Journal of Labor Research 26(1), 155-167.

Calvino, F., C. Criscuolo, C. Menon, and A. Secchi (2018). Growth volatility and size: a firm-level study. Journal of Economic Dynamics and Control 90, 390-407.

Cioppa, T. M. and T. W. Lucas (2007). Efficient nearly orthogonal and space-filling latin hypercubes. Technometrics 49(1), 45-55.

Decker, R. A., J. Haltiwanger, R. S. Jarmin, and J. Miranda (2016). Declining business dynamism: What we know and the way forward. American Economic Review 106(5), 203-07.

Dosi, G., G. Fagiolo, M. Napoletano, A. Roventini, and T. Treibich (2015). Fiscal and monetary policies in complex evolving economies. Journal of Economic Dynamics and Control 52, 166-189.

Dosi, G., G. Fagiolo, and A. Roventini (2010). Schumpeter meeting Keynes: A policyfriendly model of endogenous growth and business cycles. Journal of Economic Dynamics and Control 34(9), 1748-1767.

Dosi, G., D. Moschella, E. Pugliese, and F. Tamagni (2015). Productivity, market selection, and corporate growth: comparative evidence across us and europe. Small Business Economics 45(3), 643-672.

Dosi, G., M. Napoletano, A. Roventini, J. E. Stiglitz, and T. Treibich (2017). Rational heuristics? expectations and behaviors in evolving economies with heterogeneous interacting agents. Expectations and Behaviors in Evolving Economies with Heterogeneous Interacting Agents (December 8, 2017).

Dosi, G., R. Nelson, and S. Winter (2001). The nature and dynamics of organizational capabilities. OUP Oxford.

Dosi, G., M. C. Pereira, A. Roventini, and M. E. Virgillito (2017). When more Flexibility Yields more Fragility: the Microfoundations of Keynesian Aggregate Unemployment. Journal of Economic Dynamics and Control 81, 162-186.

Dosi, G., M. C. Pereira, A. Roventini, and M. E. Virgillito (2018). Causes and consequences of hysteresis: aggregate demand, productivity, and employment. Industrial and Corporate Change 27(6), 1015-1044.

Dosi, G., M. C. Pereira, and M. E. Virgillito (2017). The footprint of evolutionary processes of learning and selection upon the statistical properties of industrial dynamics. Industrial and Corporate Change 26(2), 187-210.

Dosi, G., M. C. Pereira, and M. E. Virgillito (2018). On the robustness of the fat-tailed distribution of firm growth rates: a global sensitivity analysis. Journal of Economic Interaction and Coordination 13(1), 173-193.

Dunne, T., L. Foster, J. Haltiwanger, and K. R. Troske (2004). Wage and productivity dispersion in united states manufacturing: The role of computer investment. Journal of Labor Economics 22(2), 397-429. 
Ebbinghaus, B. and J. Visser (1999). When institutions matter: Union growth and decline in western europe, 1950-1995. European Sociological Review 15(2), 135-158.

Fagiolo, G., M. Guerini, F. Lamperti, A. Moneta, and A. Roventini (2017). Validation of agent-based models in economics and finance. Technical Report 2017/23, Laboratory of Economics and Management (LEM), Sant'Anna School of Advanced Studies, Pisa, Italy.

Farber, H. S., D. Herbst, I. Kuziemko, and S. Naidu (2018). Unions and inequality over the twentieth century: New evidence from survey data. Technical report, National Bureau of Economic Research.

Foster, L., C. Grim, and J. Haltiwanger (2016). Reallocation in the great recession: cleansing or not? Journal of Labor Economics 34(S1), S293-S331.

Foster, L., J. C. Haltiwanger, and C. J. Krizan (2001). Aggregate productivity growth: Lessons from microeconomic evidence. In New developments in productivity analysis, pp. 303-372. University of Chicago Press.

Freeman, R. (1980). The exit-voice tradeoff in the labor market: Unionism, job tenure, quits, and separations. Quarterly Journal of Economics 94(4), 643-673.

Freeman, R. B. (1984). Longitudinal analyses of the effects of trade unions. Journal of Labor Economics 2(1), 1-26.

Freeman, R. B. (1997). Spurts in union growth: Defining moments and social processes. Technical report, National Bureau of Economic Research.

Hibbs Jr, D. A. and H. Locking (2000). Wage dispersion and productive efficiency: Evidence for Sweden. Journal of Labor Economics 18(4), 755-782.

Hutchinson, J. and D. Persyn (2012, Apr). Globalisation, concentration and footloose firms: in search of the main cause of the declining labour share. Review of World Economics 148(1), 17-43.

Karabarbounis, L. and B. Neiman (2013). The global decline of the labor share. The Quarterly Journal of Economics 129(1), 61-103.

McGowan, M. A., D. Andrews, and V. Millot (2017). Insolvency regimes, zombie firms and capital reallocation. Technical report, OECD Economics Department Working Papers, No. 1399, OECD Publishing, Paris.

Morris, M. D. (1991). Factorial sampling plans for preliminary computational experiments. Technometrics 33(2), 161-174.

Rasmussen, C. and C. Williams (2006). Gaussian processes for machine learning. Cambridge, MA: MIT Press.

Salle, I. and M. Yildizoglu (2014). Efficient sampling and meta-modeling for computational economic models. Computational Economics 44(4), 507-536.

Saltelli, A., M. Ratto, T. Andres, F. Campolongo, J. Cariboni, D. Gatelli, M. Saisana, and S. Tarantola (2008). Global sensitivity analysis: the primer. New York: John Wiley \& Sons. 
Salter, W. (1960). Productivity \& Technical Change. Cambridge: Cambridge University Press.

Schwellnus, C., A. Kappeler, and P.-A. Pionnier (2017). Decoupling of wages from productivity. Technical report, OECD Economics Department Working Papers, No. 1373, OECD Publishing, Paris.

Sobol, I. M. (1993). Sensitivity analysis for non-linear mathematical models. Mathematical Modelling and Computational Experiments 1(4), 407-414.

Syverson, C. (2017, May). Challenges to mismeasurement explanations for the us productivity slowdown. Journal of Economic Perspectives 31(2), 165-86. 
Figure 1: Panel A: uniform wage; Panel B: wages proportional to productivity; Panel C: different wage elasticities to productivity
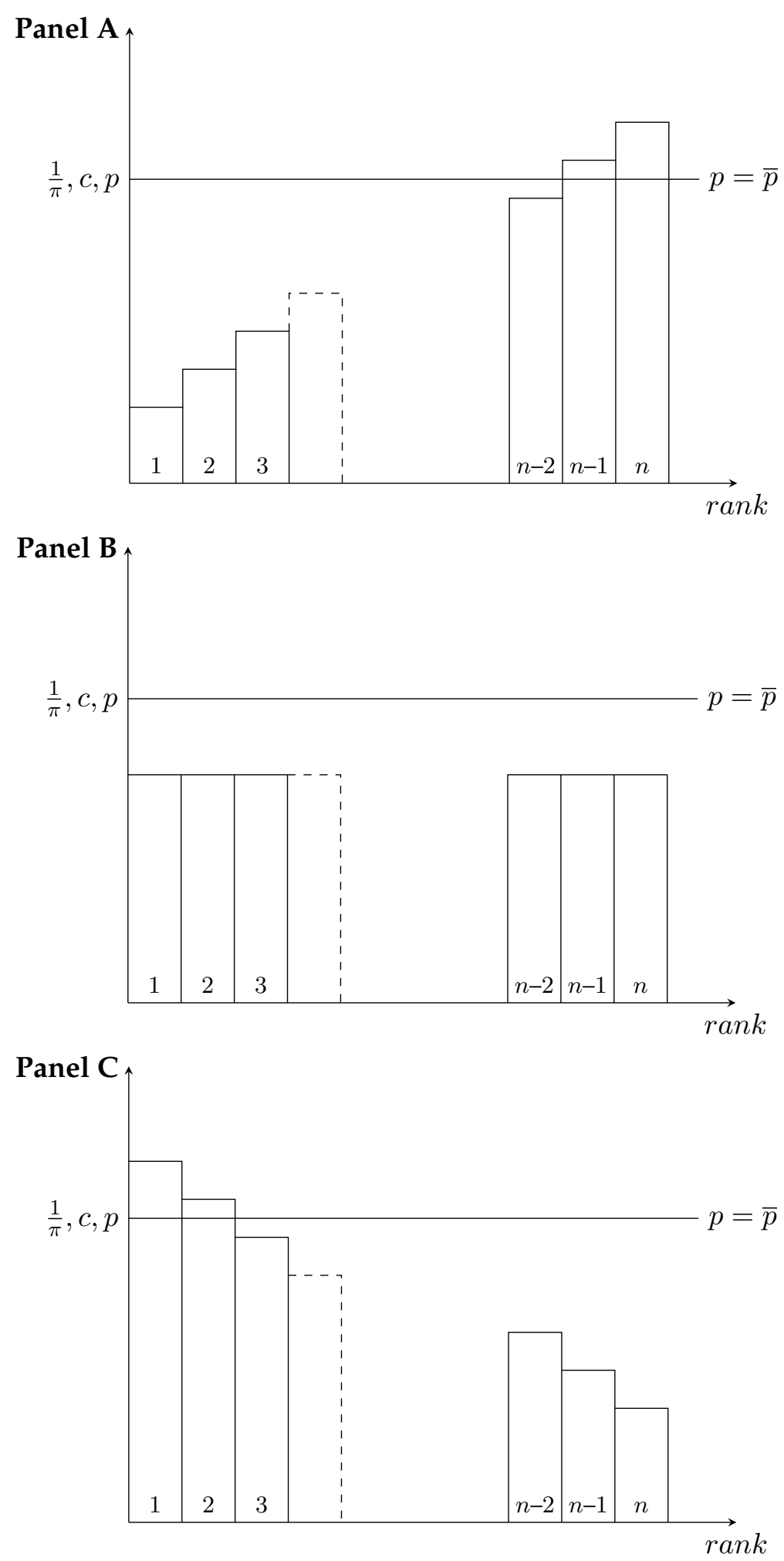
Figure 2: The model overall structure.

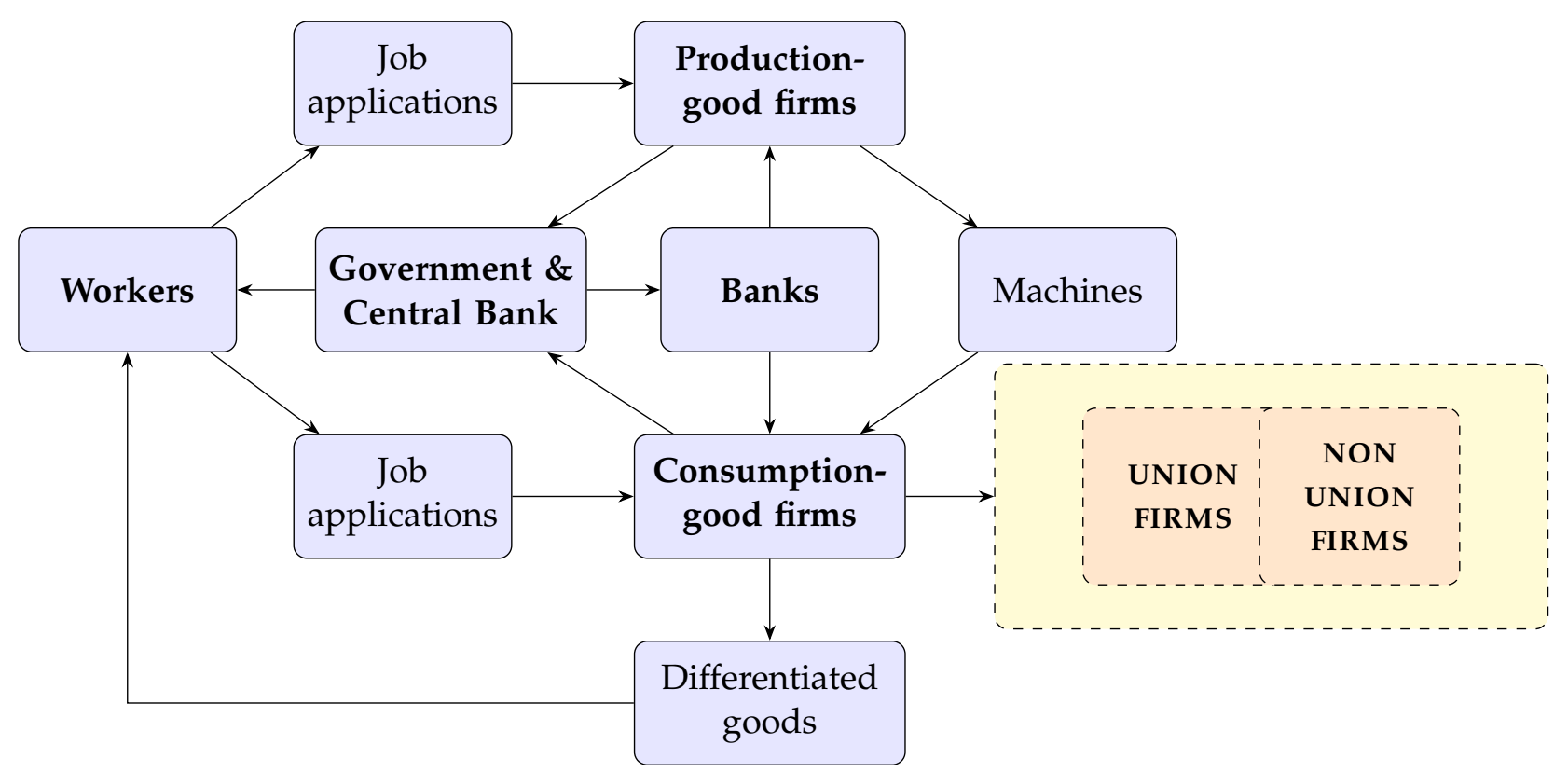

Boxes in bold style represent the model's agents. Dashed boxes represent the two variants of firms (orange) competing in the product market (yellow). 
Figure 3: Matching of stylized facts in industrial dynamics.

(a) Distribution of firm size (consumer-good sector)

(b) Gibrat's law
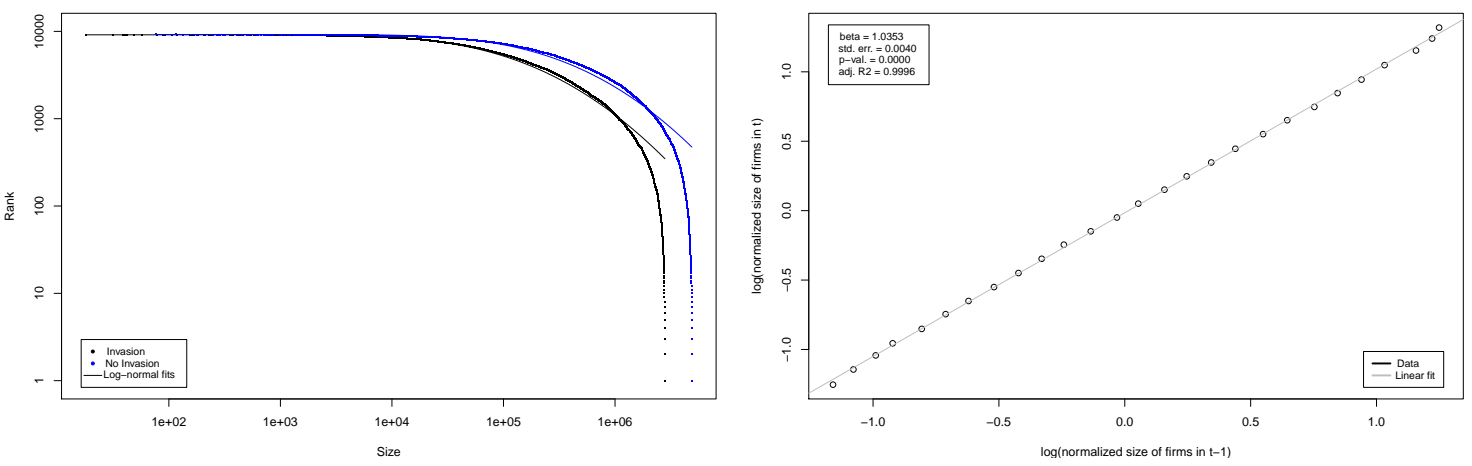

(c) Distribution of firm size growth rate (consumergood sector)

(d) Scaling of variance of firm size
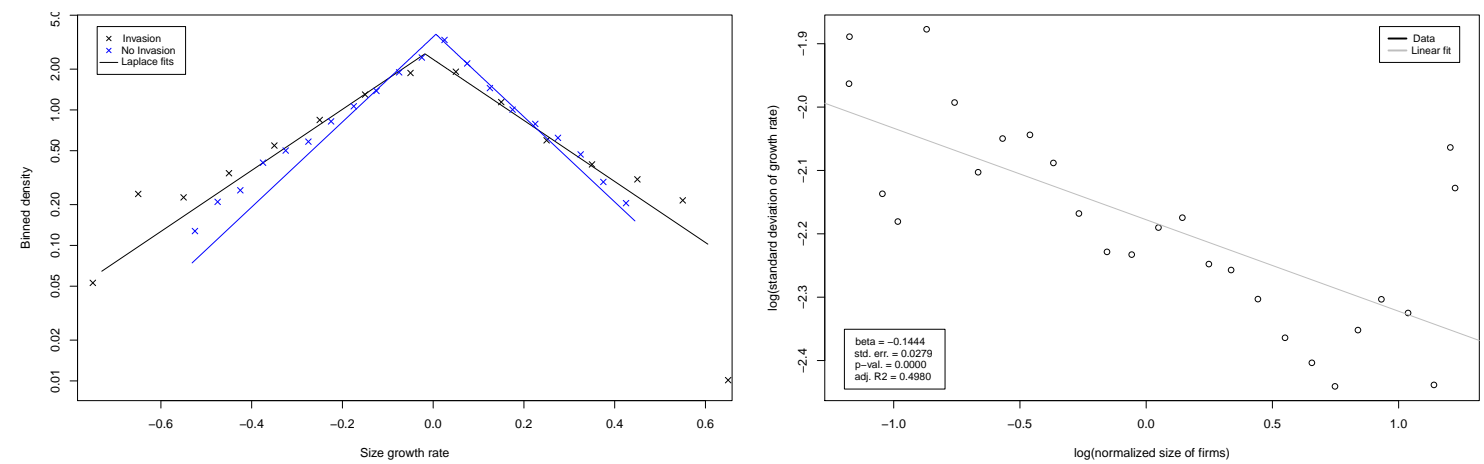

Pooled data from $100 \mathrm{MC}$ runs in period [200, 400]. 
Figure 4: Market share of non-unionised, consumer-good firms.

(a) Invasion scenario

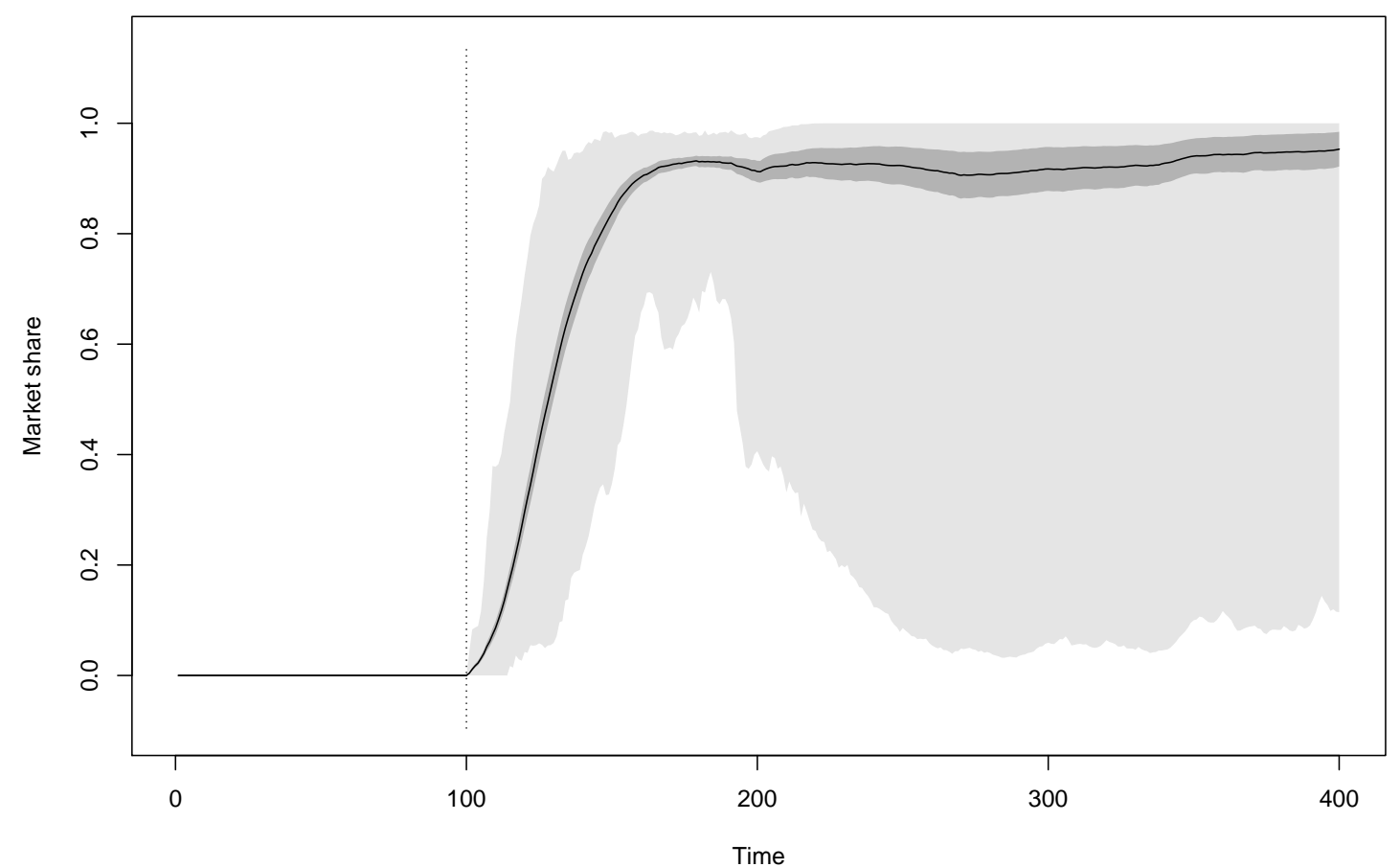

(b) No-invasion scenario

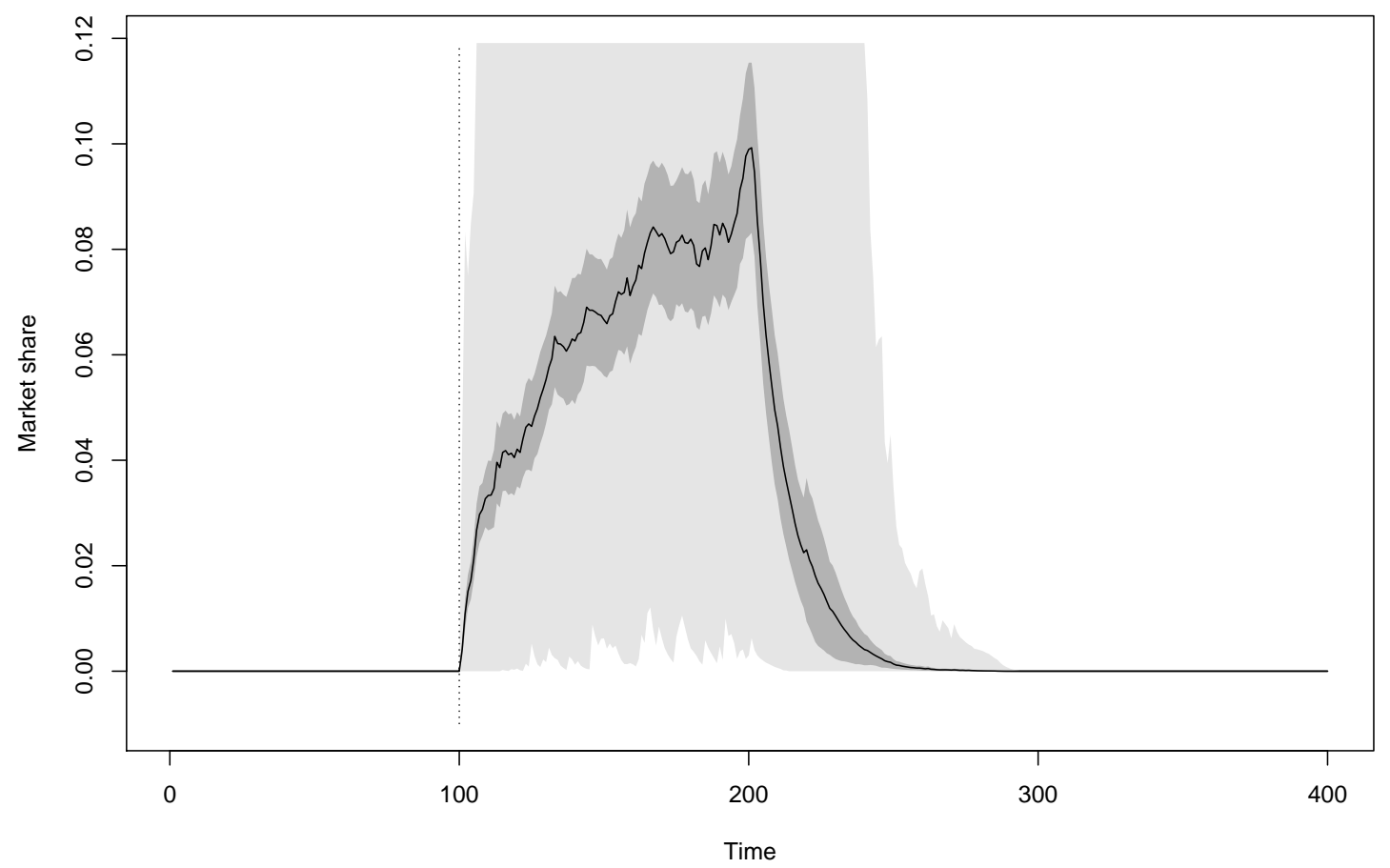

Lines: average for $100 \mathrm{MC}$ runs । Dotted lines: regime change. Dark grey bands: MC $95 \%$ confidence interval I Light grey band: MC absolute max./min. 
Figure 5: Comparison of wage dynamics between two scenarios (consumer-good sector). Pooled data from $100 \mathrm{MC}$ runs in period [200,400].

(a) Log-normalized real wage distribution

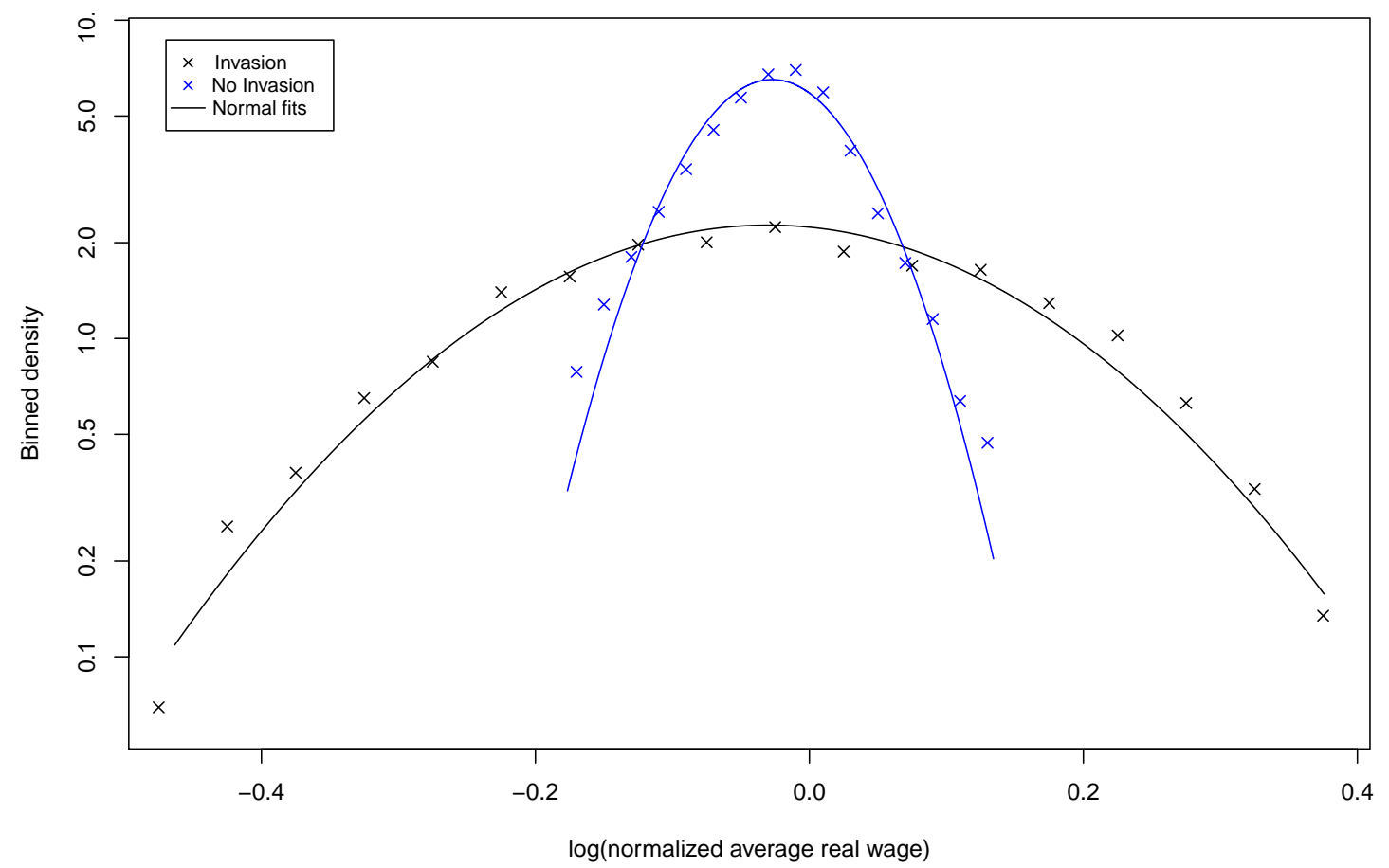

(b) Log-normalized real wage growth rate distribution

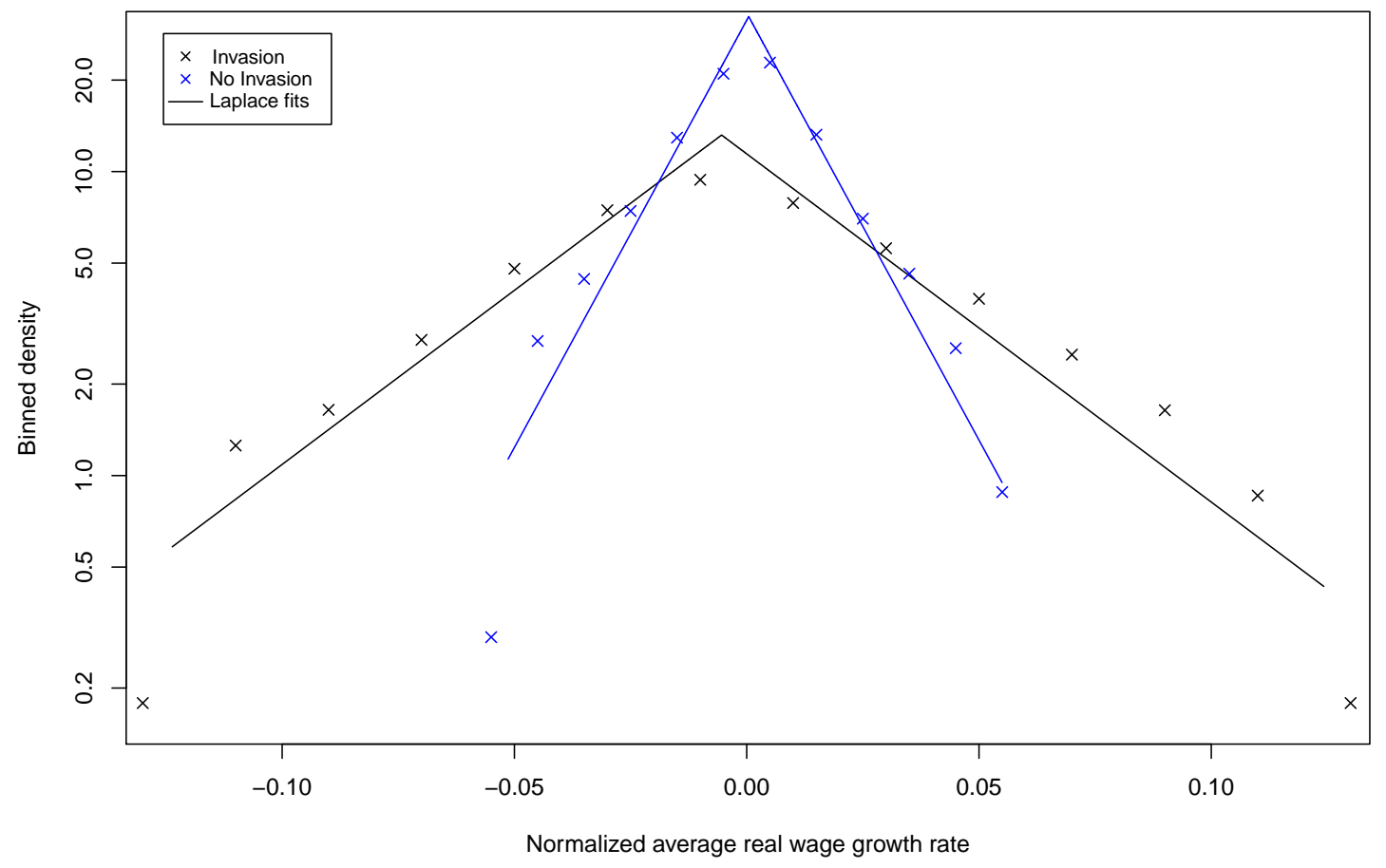


Figure 6: Performance comparison between unionised and non-unionised firms in two scenarios.

(a) Productivity growth

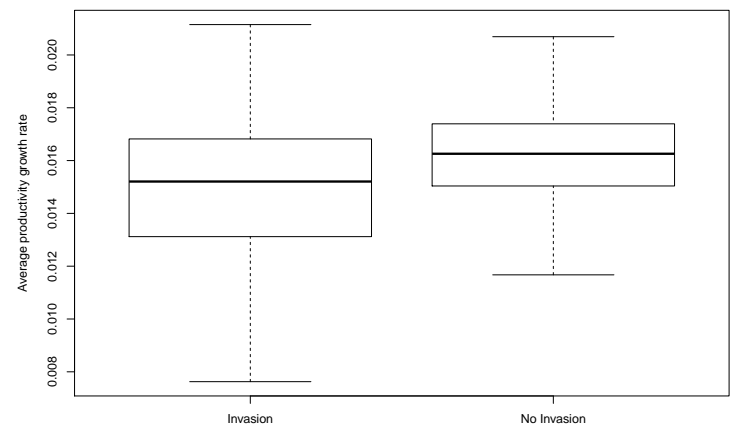

(c) Inflation (consumer-price index growth rate)

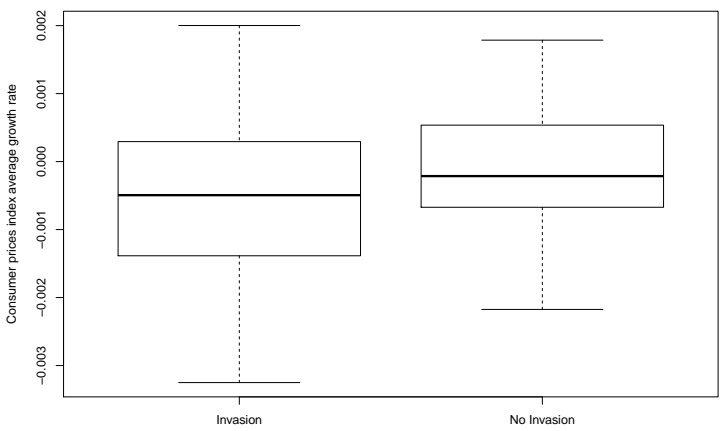

(b) Consumer-good quality index

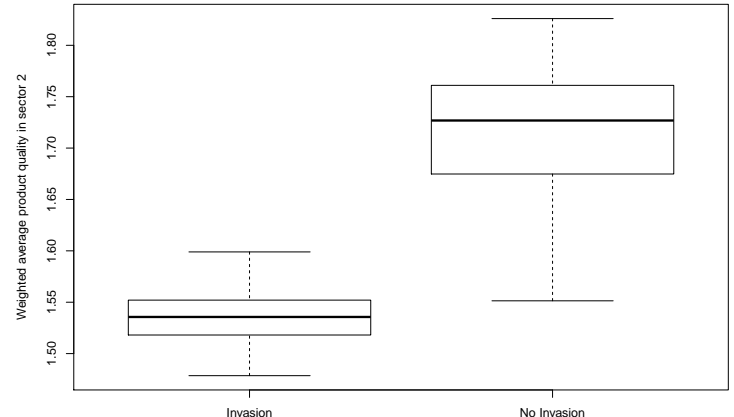

(d) Consumer-good market concentration (HerfindahlHirschman index)

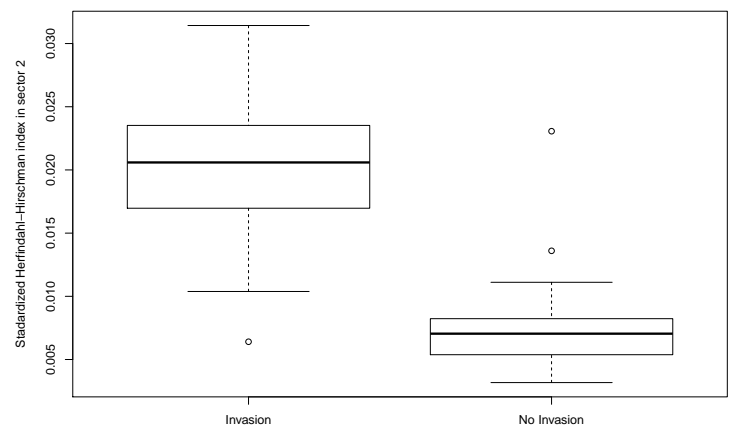

Statistics for 100 MC runs in period [200,400]. Bar: MC median I Box: MC 2nd-3rd quartile | Whiskers: MC maximum-minimum I Dots: MC outliers. 
Figure 7: Comparison of productivity dynamics by firm types between two scenarios (consumergood sector).

(a) Log-normalized productivity by firm type

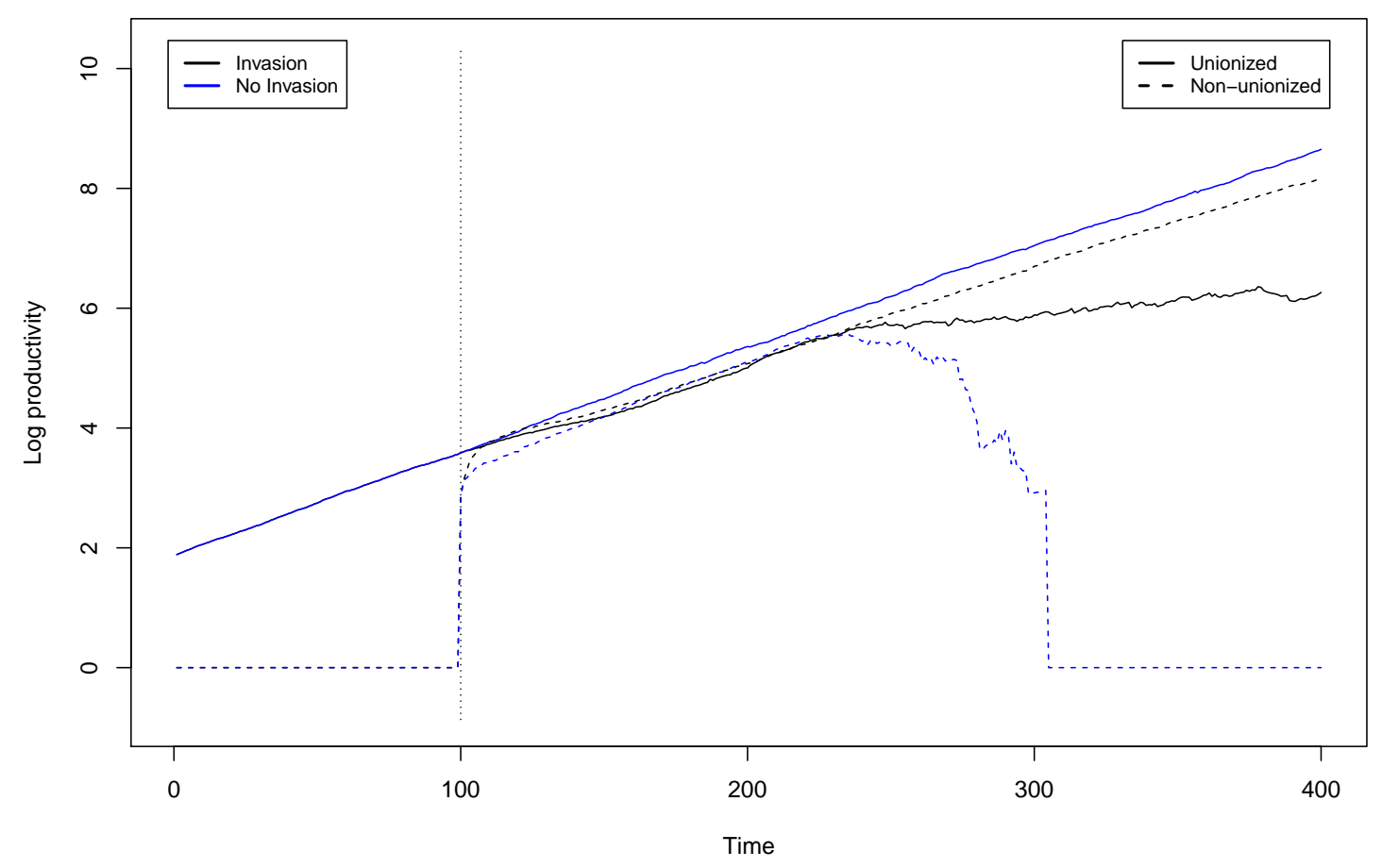

(b) Log-normalized productivity standard deviation by firm type

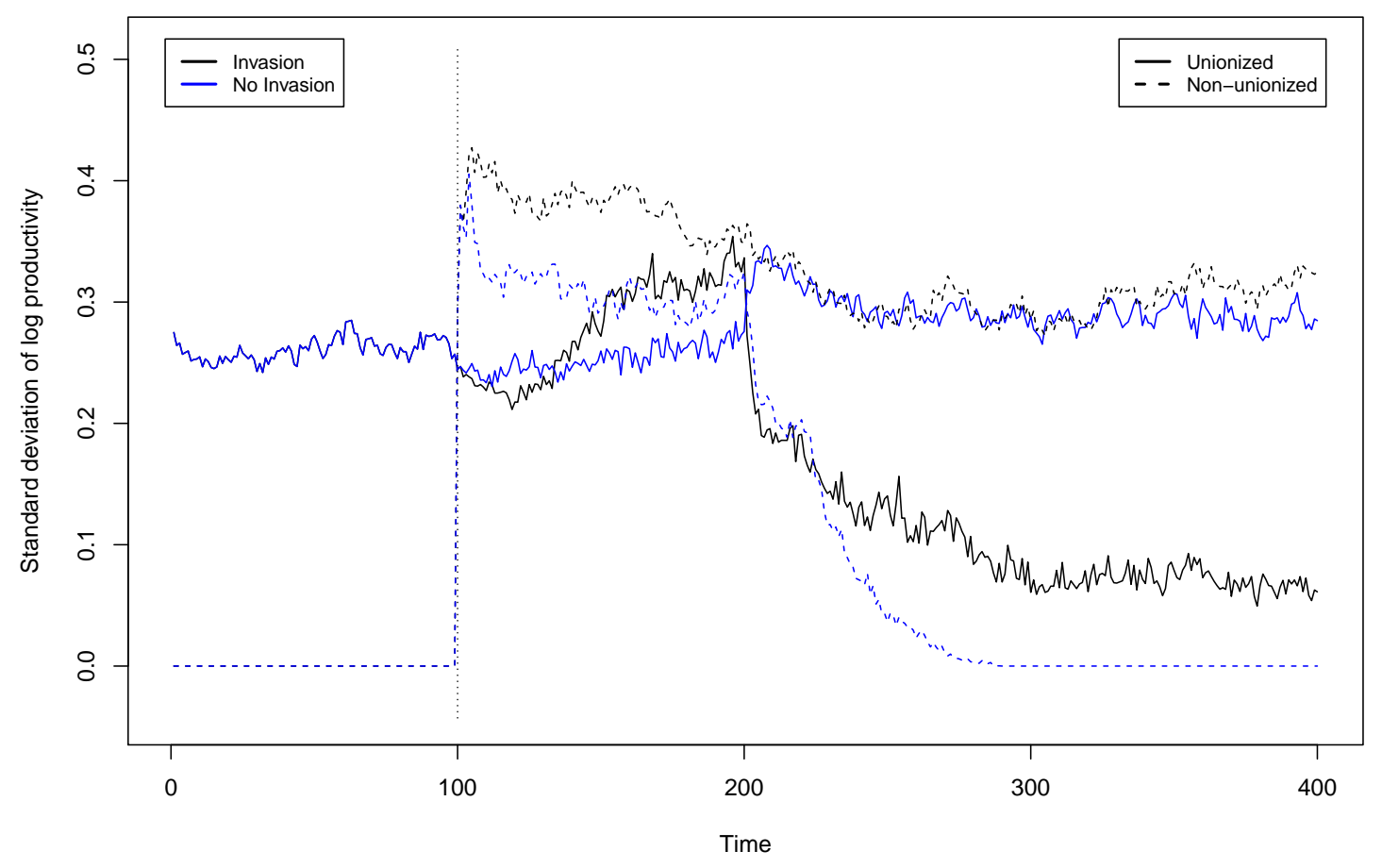

Lines: MC average for $100 \mathrm{MC}$ runs | Dotted vertical lines: regime change. 
Figure 8: Correlation between real wage and productivity in two scenarios, representative runs.

(a) Invasion scenario

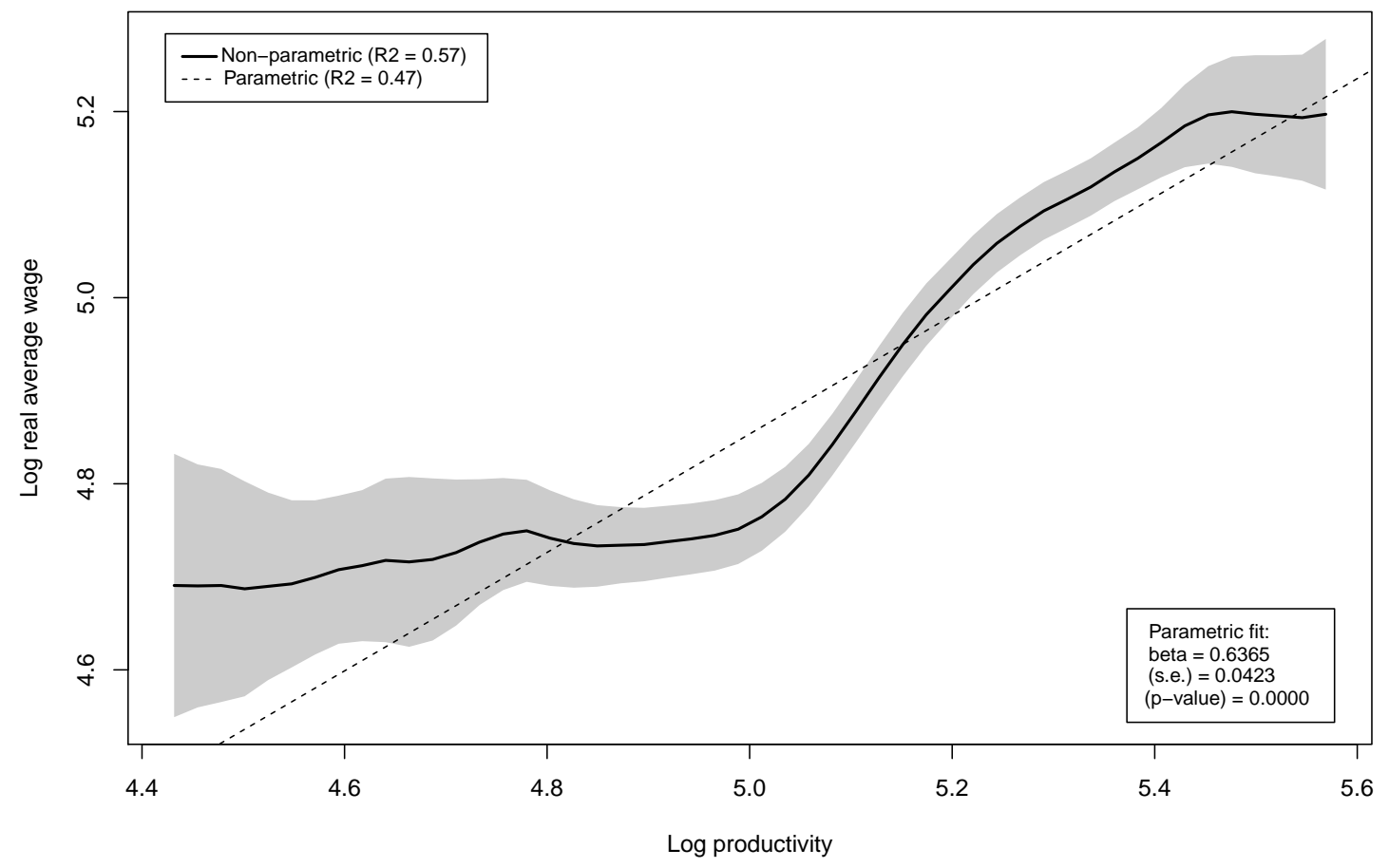

(b) No-invasion scenario

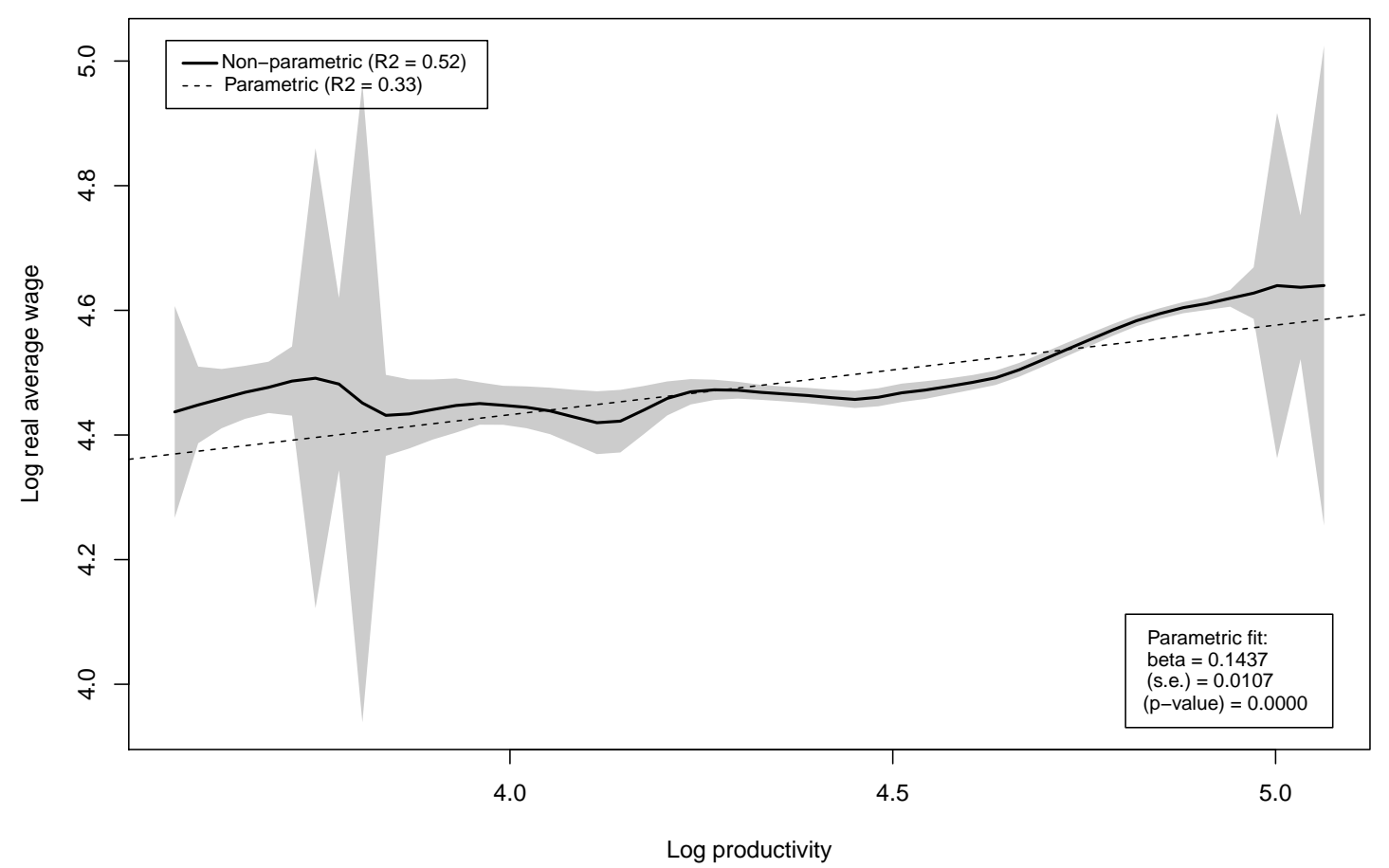

Epanechnikov-kernel, non-parametric, and ordinary least squares parametric fits. Single-run data from period 200. Grey bands: non-parametric fit $95 \%$ confidence interval. 
Figure 9: Dynamic path of the impacts of deunionization on outcomes

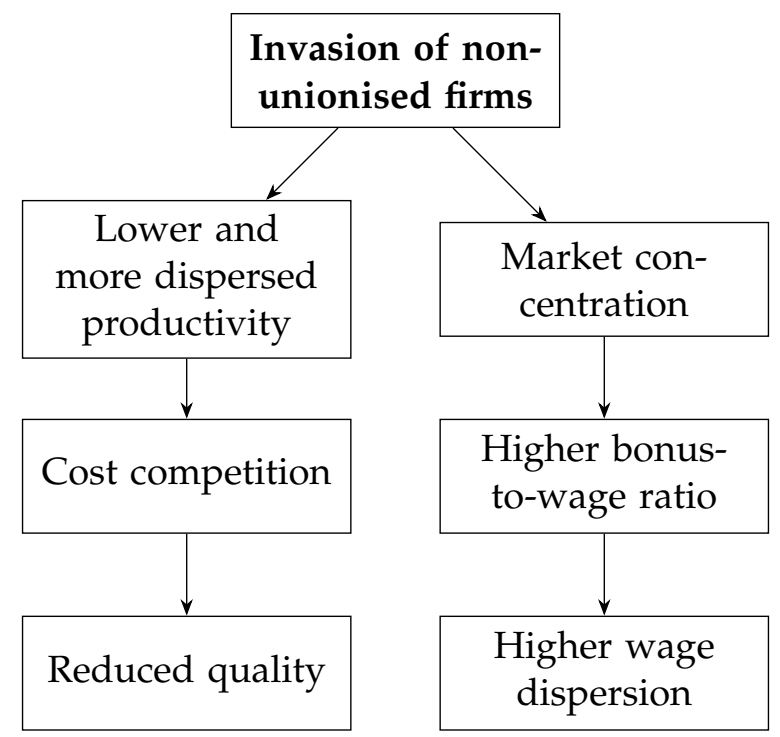


Table 1: Characteristics of the two types of firms.

\begin{tabular}{|c|c|c|}
\hline FIRMS BEHAVIOUR & UNION & NON-UNION \\
\hline Differentiated wages & no & yes \\
\hline Wage sensitivity to unemployment & low (rigid) & high (flexible) \\
\hline Wage indexation to average productivity & full & partial \\
\hline Labour-firing restrictions & under losses only & none \\
\hline Worker-hiring rule & higher skills & depends on scenario \\
\hline Worker-firing rule & lower skills & depends on scenario \\
\hline Worker new-job search intensity & $\operatorname{low}(\omega=2)$ & $\operatorname{high}(\omega=5)$ \\
\hline \multicolumn{3}{|l|}{ SCENARIOS } \\
\hline \multirow{4}{*}{ No-invasion } & Hire (fire) workers with & Hire (fire) workers with \\
\hline & lower (higher) skill first & lower (higher) wage-to-skill ratio first \\
\hline & Hire (fire) workers with & Hire (fire) workers with \\
\hline & lower (higher) skill first & lower (higher) wage first \\
\hline
\end{tabular}


Table 2: Stylized facts matched by the $\mathrm{K}+\mathrm{S}$ model at different aggregation levels.

\begin{tabular}{|c|c|}
\hline MICROECONOMIC STYLIZED FACTS & AGGREGATE-LEVEL STYLIZED FACTS \\
\hline Skewed firm size distribution & $\begin{array}{l}\text { Endogenous self-sustained growth } \\
\text { with persistent fluctuations }\end{array}$ \\
\hline Fat-tailed firm growth rates distribution & Fat-tailed GDP growth rate distribution \\
\hline Heterogeneous productivity across firms & $\begin{array}{l}\text { Endogenous volatility of GDP, } \\
\text { consumption and investment }\end{array}$ \\
\hline Persistent productivity differentials & Cross-correlation of macro variables \\
\hline Lumpy investment rates of firms & $\begin{array}{l}\text { Pro-cyclical aggregate R\&D investment } \\
\text { and net entry of firms in the market }\end{array}$ \\
\hline Heterogeneous skills distribution & Persistent and counter-cyclical unemployment \\
\hline Fat-tailed unemployment time distribution & Endogenous volatility of productivity, \\
\hline \multirow[t]{7}{*}{ Fat-tailed wage growth rates distribution } & unemployment, vacancy, separation and \\
\hline & Unemployment and inequality correlation \\
\hline & Pro-cyclical workers skills accumulation \\
\hline & Beveridge curve \\
\hline & Okun curve \\
\hline & Wage curve \\
\hline & Matching function \\
\hline
\end{tabular}

Source: Dosi et al. (2017). 
Table 3: Performance comparison between baseline and alternative scenario, selected time series.

\begin{tabular}{rccc}
\hline & INVASION & \multicolumn{2}{c}{ No INVASION } \\
& Baseline & Ratio & $p$-value \\
\hline GDP growth & 0.014 & 1.176 & 0.000 \\
Productivity growth & 0.014 & 1.138 & 0.000 \\
Inflation (CPI) & -0.001 & 0.215 & 0.009 \\
Quality index & 1.535 & 1.118 & 0.000 \\
Market concentration (HHI) & 0.020 & 0.350 & 0.000 \\
Wages standard deviation & 0.223 & 0.501 & 0.000 \\
Bonus-to-wage ratio & 0.024 & 0.817 & 0.000 \\
Gini index & 0.209 & 0.447 & 0.000
\end{tabular}

Baseline values are averages for $100 \mathrm{MC}$ runs in period [200,400]. Ratios between baseline and alternative scenario MC averages. $p$-values for a two-means $t$-test among scenarios, $H_{0}$ : no difference between scenarios. 
Table 4: Shift-and-share decomposition of log-normalized labour productivity growth in two scenarios.

\begin{tabular}{rccccccc}
\hline INVASION & TOTAL & WITHIN & BETWEEN & CROSS & ENTRY & EXIT & UNEXPL. \\
\hline Overall & 21.74 & 17.69 & 9.44 & -6.33 & 3.66 & -3.78 & 5.37 \\
& $(0.64)$ & $(0.59)$ & $(0.72)$ & $(0.39)$ & $(1.00)$ & $(1.13)$ & $(0.38)$ \\
Union & -0.55 & 1.11 & 2.81 & -0.70 & 1.24 & -4.59 & 2.07 \\
& $(0.84)$ & $(0.27)$ & $(0.57)$ & $(0.17)$ & $(0.22)$ & $(0.60)$ & $(0.54)$ \\
Non-union & 22.29 & 16.58 & 6.63 & -5.62 & 2.42 & 0.81 & 6.50 \\
& $(1.09)$ & $(0.65)$ & $(0.66)$ & $(0.31)$ & $(0.80)$ & $(0.60)$ & $(0.59)$ \\
\hline No INVASION & TOTAL & WITHIN & BETWEEN & CROSS & ENTRY & EXIT & UNEXPL. \\
\hline Overall & 25.08 & 20.16 & 8.53 & -8.82 & 0.77 & 0.74 & 3.96 \\
& $(0.40)$ & $(0.50)$ & $(0.33)$ & $(0.35)$ & $(0.46)$ & $(0.70)$ & $(0.25)$ \\
Union & 29.97 & 20.12 & 10.38 & -8.78 & -0.76 & 4.50 & 4.78 \\
& $(0.61)$ & $(0.51)$ & $(0.37)$ & $(0.35)$ & $(0.23)$ & $(0.34)$ & $(0.39)$ \\
Non-union & -4.88 & 0.04 & -1.85 & -0.03 & 1.52 & -3.76 & 0.07 \\
& $(0.45)$ & $(0.02)$ & $(0.18)$ & $(0.01)$ & $(0.25)$ & $(0.40)$ & $(0.06)$ \\
\hline
\end{tabular}

Moving averages for $100 \mathrm{MC}$ runs over an 8-period window in period [200,400]. MC standard errors in parentheses. 
Table 5: (Log) real wages vs. (log) productivity, two scenarios.

\begin{tabular}{rcc}
\hline & INVASION & NO INVASION \\
\hline Intercept $(\alpha)$ & 1.575 & 4.308 \\
& $(0.120)$ & $(0.098)$ \\
Slope ( $\beta$ ) & 0.634 & 0.142 \\
& $(0.025)$ & $(0.011)$ \\
$p$-value ( $\beta$ ) & 0.006 & 0.018 \\
& $(0.004)$ & $(0.008)$ \\
$R^{2}$ (parametric) & 0.377 & 0.239 \\
$R^{2}$ (non-parametric) & $(0.016)$ & $(0.018)$ \\
& 0.487 & 0.321 \\
Observations (firms) & $(0.016)$ & $(0.021)$ \\
& 310.4 & 339.6 \\
& $(4.333)$ & $(5.020)$
\end{tabular}

Ordinary least squares (parametric) and Epanechnikov-kernel (non-parametric) fits. Averages for $100 \mathrm{MC}$ runs in period 200. MC standard errors in parentheses. 


\section{Appendix A}

\section{Model description: Technical change, investment and entry}

The technology of capital-good firms is defined as $\left(A_{i}^{\tau}, B_{i}^{\tau}\right) . A_{i}^{\tau}$ is the labour productivity of the machine-tool manufactured by firm $i$ for the consumption-good sector, while $B_{i}^{\tau}$ is the labour productivity to produce the machine. Superscript $\tau$ denotes the technology vintage being produced/used. Given the monetary average wage $w_{i, t}$ paid by firm $i$, its unit cost of production is:

$$
c_{i, t}=\frac{w_{i, t}}{B_{i}^{\tau}}
$$

Under a fixed mark-up $\mu_{1} \in \mathbb{R}_{+}$pricing rule, price $p_{i, t}$ od firm $i$ is defined as:

$$
p_{i, t}=\left(1+\mu_{1}\right) c_{i, t}
$$

Firms in the capital-good industry adaptively strive to increase market shares and profits by improving technology via innovation and imitation. Firms invest in R\&D a fraction $\nu \in[0,1]$ of their past sales $S_{i, t-1}$ :

$$
R D_{i, t}=\nu S_{i, t-1}
$$

R\&D activity is performed by workers devoted to this activity, whose demand is:

$$
L_{i, t}^{R \& D}=\frac{R D_{i, t}}{w_{i, t}}
$$

Firms split their R\&D workers $L_{i, t}^{R \& D}$ between innovation $\left(I N_{i, t}\right)$ and imitation $\left(I M_{i, t}\right)$ activities according to the parameter $\xi \in[0,1]$ :

$$
\begin{gathered}
I N_{i, t}=\xi L_{i, t}^{R \& D}, \\
I M_{i, t}=(1-\xi) L_{i, t}^{R \& D} .
\end{gathered}
$$

Innovation is a two-step process. The first determines whether a firm obtains or not access to an innovation - irrespectively of whether it will ultimately be a success or a failure - through a draw from a Bernoulli distribution with mean:

$$
\theta_{i, t}^{i n}=1-e^{-\zeta_{1} I N_{i, t}}
$$

with parameter $\zeta_{1} \in[0,1]$. If a firm innovates, it may draw a new machine-embodying technology $\left(A_{i, t}^{i n}, B_{i, t}^{i n}\right)$ according to:

$$
\begin{aligned}
& A_{i, t}^{i n}=A_{i, t}\left(1+x_{i, t}^{A}\right), \\
& B_{i, t}^{i n}=B_{i, t}\left(1+x_{i, t}^{B}\right),
\end{aligned}
$$

where $x_{i, t}^{A}$ and $x_{i, t}^{B}$ are two independent draws from a $\operatorname{Beta}\left(\alpha_{1}, \beta_{1}\right)$ distribution, $\left(\alpha_{1}, \beta_{1}\right) \in$ $\mathbb{R}_{+}^{2}$ over the fixed support $\left[\underline{x}_{1}, \bar{x}_{1}\right] \subset \mathbb{R}$.

Imitation also follows a two-step procedure. The access to imitation come from sampling a Bernoulli with mean:

$$
\theta_{i, t}^{i m}=1-e^{-\zeta_{2} I M_{i, t}}
$$


being parameter $\zeta_{2} \in[0,1]$. Firms accessing the second stage may copy technology $\left(A_{i}^{i m}, B_{i}^{i m}\right)$ from a close competitor and select the machine to produce using the rule:

$$
\min \left[p_{i, t}^{h}+b c_{A_{i}^{h}, j, t}^{h}\right], \quad h=\tau, i n, i m,
$$

where $b \in \mathbb{R}_{+}$is a payback parameter.

Firms in consumption-good sector do not conduct R\&D, instead they access new technologies incorporating new machines to their existing capital stock $\Xi_{j, t}$. Firms invest according to expected demand $D_{j, t}^{e}$, computed by an adaptive rule:

$$
D_{j, t}^{e}=g\left(D_{j, t-1}, D_{j, t-2}, D_{j, t-h}\right), \quad 0<h<t,
$$

where $D_{j, t-h}$ is the actual demand faced by firm $j$ at time $t-h . h \in \mathbb{N}_{*}$ is a parameter and $g: \mathbb{R}^{h} \rightarrow \mathbb{R}_{+}$is the expectation function, usually an unweighed moving average over 4 periods. The corresponding desired level of production $Q_{j, t}^{d}$, considering the actual inventories $N_{j, t}$ from previous period, is:

$$
Q_{j, t}^{d}=(1+\iota) D_{j, t}^{e}-N_{j, t-1},
$$

being $N_{j, t}^{d}=\iota D_{j, t}^{e}$ the desired inventories and $\iota \in \mathbb{R}_{+}$a parameter.

If the desired capital stock $K_{j}^{d}$ - computed as a linear function of the desired level of production $Q_{j, t}^{d}-$ is higher than the current $K_{j, t}$, firms invest $E I_{j, t}^{d}$ to expand capacity:

$$
E I_{j, t}^{d}=K_{j, t}^{d}-K_{j, t-1} .
$$

Replacement investment $S I_{j, t}^{d}$, to substitute a set $R S_{j, t}$ of existing machines by more productive ones, is decided according to a fixed payback period $b \in \mathbb{R}_{+}$. Machines $A_{i}^{\tau} \in$ $\Xi_{j, t}$ are evaluated by the ratio between the price of new machines and the corresponding cost savings:

$$
R S_{j, t}=\left\{A_{i}^{\tau} \in \Xi_{j, t}: \frac{p_{i, t}^{*}}{c_{j, t}^{A_{i}^{\tau}}-c_{j, t}^{*}} \leq b\right\}
$$

where $p_{i, t}^{*}$ and $c_{j, t}^{*}$ are the price and unit cost of production upon the selected new machine.

Prospective firms in both sectors decide on entry based on the number $F_{t-1}^{z}(z=1,2)$ and financial conditions of incumbents. The number of entrants in sector $z$ is:

$$
b_{t}^{z}=\max \left[\left(o \pi_{t}^{z}+(1-o) M A_{t}^{z}\right) F_{t-1}^{z}, 0\right], \quad z=1,2,
$$

being $o \in[0,1]$ a mix parameter and $\pi_{t}^{z}$ a uniform random draw on the fixed support $\left[\underline{x}_{2}^{z}, \bar{x}_{2}^{z}\right]$ representing the idiosyncratic component in the entry process. The sectoral market attractiveness $M A_{t}^{z}$ is evaluated based on the dynamics of firms' balance sheets:

$$
\left.M A_{t}^{z}=M C_{t}^{z}-M C_{t-1}^{z} \quad \text { (bounded to }\left[\underline{x}_{2}^{z}, \bar{x}_{2}^{z}\right]\right),
$$

defined as the (log) ratio between the aggregate sectoral stocks of liquid assets $N W_{t-1}^{z}$ (bank deposits) and debt $D e b_{t-1}^{z}$ (bank loans):

$$
M C_{t}^{z}=\log N W_{t-1}^{z}-\log D e b_{t-1}^{z} .
$$




\section{Labour search-and-match}

Labour demand in the consumption-good sector $L_{j, t}^{d}$ is determined by desired production $Q_{j, t}^{d}$ and the average productivity of current capital stock $A_{j, t}$ :

$$
L_{j, t}^{d}=\frac{Q_{j, t}^{d}}{A_{j, t}} .
$$

In the capital-good sector, instead, $L_{i, t}^{d}$ considers orders $Q_{i, t}$ and labour productivity $B_{i, t}$. In what follows, only the behaviour of the consumption-good firms (subscript $j$ ) is shown but capital-good sector operate under the same rules, except it follows the wage offers from top-paying firms in the consumption-good sector.

Firms decide whether to hire (or fire) workers according to the expected production $Q_{j, t}^{d}$. If it is increasing, $\Delta L_{j, t}^{d}$ new workers are (tentatively) hired in addition to the existing number $L_{j, t-1}$. Each firm (expectedly) get a fraction of the number of applicant workers $L_{a, t}$ in its candidates queue $\left\{\ell_{j, t}^{s}\right\}$, proportional to firm market share $f_{j, t-1}$ :

$$
\mathrm{E}\left(L_{j, t}^{s}\right)=\left(\omega\left(1-U_{t-1}\right)+\omega_{u} U_{t-1}\right) L^{S} f_{j, t-1},
$$

where $L^{S}$ is the (fixed) total labour supply, $U_{t}$ is the unemployment rate and $\omega, \omega_{u} \in \mathbb{R}_{+}$ are parameters defining the number of applications each job seeker sends if employed or unemployed, respectively. Considering the set of workers in $\left\{\ell_{j, t}^{s}\right\}$, each firm select the subset of desired workers $\left\{\ell_{j, t}^{d}\right\}$ to make a job (wage) offer:

$$
\left\{\ell_{j, t}^{d}\right\}=\left\{\ell_{j, t} \in\left\{\ell_{j, t}^{s}\right\}: w_{\ell, t}^{r} \leq w_{j, t}^{o}\right\} .
$$

Firms target workers that would accept the wage offer $w_{j, t}^{o}$, considering the wage $w_{\ell, t}^{r}$ requested by workers, if any. Firm $j$ hires up to the total demand $L_{j, t}^{d}$ or up to all workers in the queue, whichever is lower. The total number of workers $L_{j, t}$ the firm will employ in $t$, given the current workforce $L_{j, t-1}$, is bound by:

$$
0 \leq L_{j, t} \leq L_{j, t}^{d} \leq L_{j, t}^{s}, \quad L_{j, t}^{z}=L_{j, t-1}+\#\left\{\ell_{j, t}^{z}\right\}, \quad z=d, s .
$$

The search, wage determination and firing processes differ according to the configuration. When there is no negotiation, firm $j$ offers the wage:

$$
w_{j, t}^{o}=w_{j, t-1}^{o}\left(1+W P_{j, t}+\mathrm{N}\left(0, w_{e r r}^{o}\right)\right) \quad \text { bounded to } p_{j, t-1} A_{j, t-1},
$$

that is accepted by the worker if she has no better offer. The wage premium is defined as:

$$
W P_{j, t}=\psi_{2} \frac{\Delta A_{t}}{A_{t-1}}+\psi_{4} \frac{\Delta A_{j, t}}{A_{j, t-1}}, \quad \psi_{1}+\psi_{2} \leq 1,
$$

being $A_{t}$ the aggregate labour productivity, $\Delta$ the time difference operator, and $\left(\psi_{1}, \psi_{2}\right) \in$ $\mathbb{R}_{+}^{2}$ parameters. $w_{j, t}^{o}$ is also applied to existing workers. $w_{j, t}^{o}$ is bounded to the breakeven wage (zero unit profits myopic expectation). When one-round of negotiation exists, workers have reservation wages equal to the unemployment benefit, if any, and request a wage $w_{\ell, t}^{r}$ in the job application:

$$
w_{\ell, t}^{r}=\left\{\begin{array}{ll}
w_{\ell, t-1}(1+\epsilon) & \text { if employed in } \mathrm{t}-1 \\
w_{\ell, t}^{s} & \text { if unemployed in } \mathrm{t}-1
\end{array} .\right.
$$


$w_{\ell, t}$ is the current wage for the employed workers and $\epsilon \in \mathbb{R}_{+}$, a parameter. Unemployed workers have a shrinking satisfying wage $w_{\ell, t}^{s}$, accounting for the wage history:

$$
w_{\ell, t}^{s}=\max \left(w_{t}^{u}, \frac{1}{T_{s}} \sum_{h=1}^{T_{s}} w_{\ell, t-h}\right),
$$

being $T_{s} \in \mathbb{N}_{*}$, the moving average time-span parameter. An employed worker accepts the best offer $w_{j, t}^{o}$ she receives if higher than current wage $w_{\ell, t}$. An unemployed worker accepts the best offer if at least equal to the unemployment benefit $w_{t}^{u}$.

Government imposes a minimum wage $w_{t}^{\text {min }}$ on firms, indexed on aggregate productivity $A_{t}$ :

$$
w_{t}^{\min }=w_{t-1}^{\min }\left(1+\psi_{1} \frac{\Delta A_{t}}{A_{t-1}}\right) \text {. }
$$

\section{Banks, government, and consumption}

There are $B$ commercial banks (subscript $k$ ) which take deposits and provide credit to firms. Bank-firm pairs are set randomly and are stable along firms' lifetime. Bank profits come from interest received on loans $\left(\right.$ Loans $\left._{k, t}\right)$ and on reserves at the central bank $\left(\operatorname{Res}_{k, t}\right)$ deducted from interest paid on deposits $\left(D e p o_{k, t}\right)$ and from losses from defaulted loans $\left(\right.$ BadDeb $\left._{k, t}\right)$ :

$$
\Pi_{k, t}^{b}=r^{\text {deb }} \text { Loans }_{k, t}+r^{r e s} \operatorname{Res}_{k, l}-r_{D} \text { Depo }_{k, t}-\text { BadDeb }_{k, t},
$$

being $\left(r^{d e b}, r, r_{D}\right) \in \mathbb{R}_{+}^{3}$ the interest rates on debt, bank reserves, and deposits, respectively.

Government taxes firms and banks profits at a fixed rate $t r \in \mathbb{R}_{+}$:

$$
\operatorname{Tax}_{t}=\left(\Pi_{t}^{1}+\Pi_{t}^{2}+\Pi_{t}^{b}\right) t r,
$$

where $\Pi_{t}^{1}, \Pi_{t}^{2}$ and $\Pi_{t}^{b}$ are the aggregate total profits of the capital-good, the consumer-good and the banking sectors, respectively. It pays to unemployed workers a benefit $w_{t}^{u}$ which is a fraction of the current average wage $\bar{w}_{t}$ :

$$
w_{t}^{u}=\psi \bar{w}_{t-1},
$$

where $\psi \in[0,1]$ is a parameter. The recurring total public expenditure $G_{t}$ and the public primary deficit (or surplus) are:

$$
\begin{gathered}
G_{t}=\left(L^{S}-L_{t}^{D}\right) w_{t}^{u} . \\
D e f_{t}=G_{t}-\text { Tax }_{t},
\end{gathered}
$$

The stock of public debt is updated as in:

$$
D e b_{t}=D e b_{t-1}+D e f_{t}-\Pi_{t}^{c b}+G_{t}^{b a i l},
$$

where $\Pi_{t}^{c b}$ is the operational result (profits/losses) of the central bank and $G_{t}^{b a i l}$ is the cost of rescuing (bail-out) the banking sector during financial crises, if any.

Workers fully consume their income (if possible) and do not get credit. Accordingly, desired aggregate consumption $C_{t}^{d}$ depends on the income of both employed and unemployed workers plus the desired unsatisfied consumption from previous periods:

$$
C_{t}^{d}=\sum_{\ell} w_{\ell, t}+G_{t}+\left(C_{t-1}^{d}-C_{t-1}\right) .
$$


The effective consumption $C_{t}$ is bound by the real production $Q_{t}^{2}$ of the consumption-good sector:

$$
C_{t}=\min \left(C_{t}^{d}, Q_{t}^{2}\right), \quad Q_{t}^{2}=\sum_{j} Q_{j, t}
$$

The model applies the standard national account identities by the aggregation of agents' stocks and flows. The aggregate value added by capital- and consumption-good firms $Y_{t}$ equals their aggregated production $Q_{t}^{1}$ and $Q_{t}^{2}$, respectively (there are no intermediate goods). That is equal to the sum of the effective consumption $C_{t}$, the total investment $I_{t}$ and the change in firm's inventories $\Delta N_{t}$ :

$$
Q_{t}^{1}+Q_{t}^{2}=Y_{t}=C_{t}+I_{t}+\Delta N_{t}
$$

For further details, see Dosi et al. (2010), Dosi et al. (2015) and Dosi et al. (2017).

\section{Appendix B}

\section{Further model results}

This Appendix presents graphs that show the pattern of change in several outcome variables beyond those stressed in the text.

The temporal dynamics of the $\mathrm{HH}$ index of market concentration is shown in Figure B.1(a). Market concentration increases in both scenarios as non-unionised firms enter. After the transient $(t>200)$, the index stabilizes at marginally higher levels when the invasion fails and at much higher ones when it succeeds. Figure B.1(b) shows that the invasion scenario presents significantly higher total distributed bonuses, mostly driven by the elevated profits of the few top performing firms. Figure B.1(c) shows that higher bonuses and lower wages result into a higher income inequalities. This contributes to a more skewed wage distribution as measured by the wage standard deviation in Figure B.1(d).

Figure B.2 presents the decomposition results for the shorter time lapse $[170 ; 200]$ at the end of the transient period. Panel B.2(a) includes the entire market while Panel B.2(b) shows the contribution of unionised firms and Panel B.2(c) shows the contribution of nonunionised firms, respectively.

Additionally, Figure B.3 displays two specifications for the shift-and-share decomposition over the entire post-transient period, Panel B.3(a) follows the evidence in Table 4 with employment shares while Panel B.3(b) applies output shares to the weights. The within-firm change dominates in both cases. 
Figure B.1: Comparison of market concentration (consumer-good sector) and income distribution dynamics between two scenarios.

(a) Market concentration

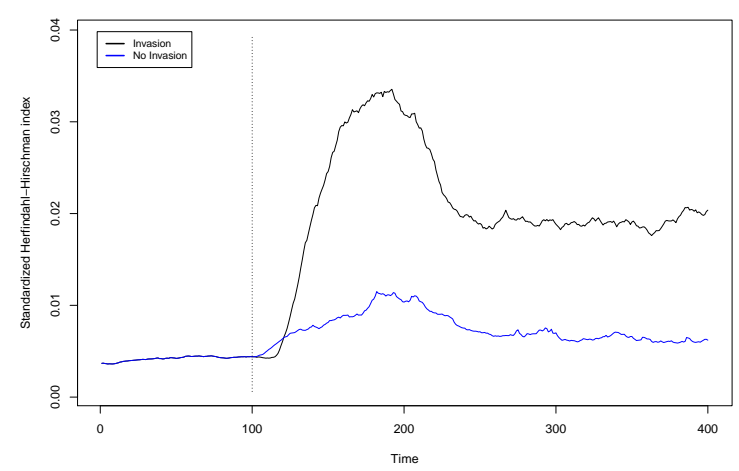

(c) Gini index

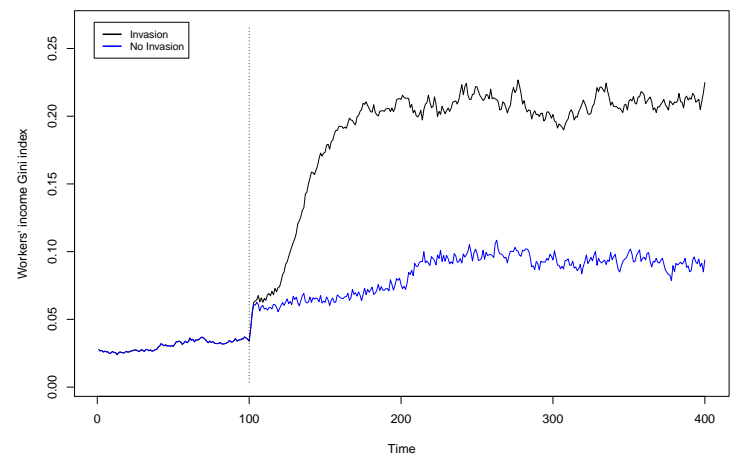

(b) Bonus share over GDP

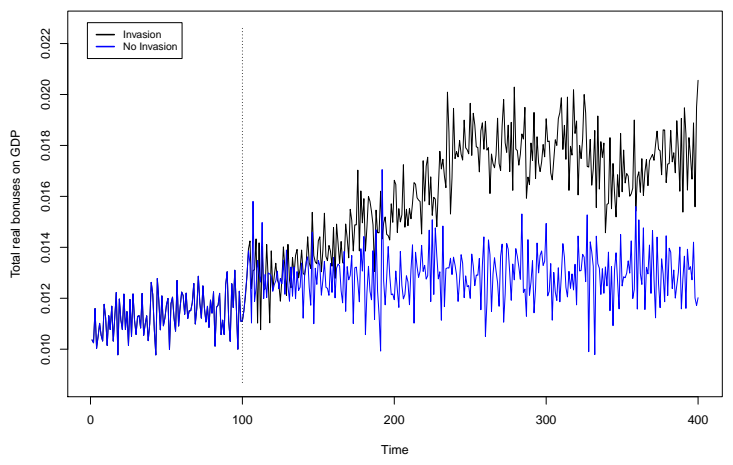

(d) Wage standard deviation

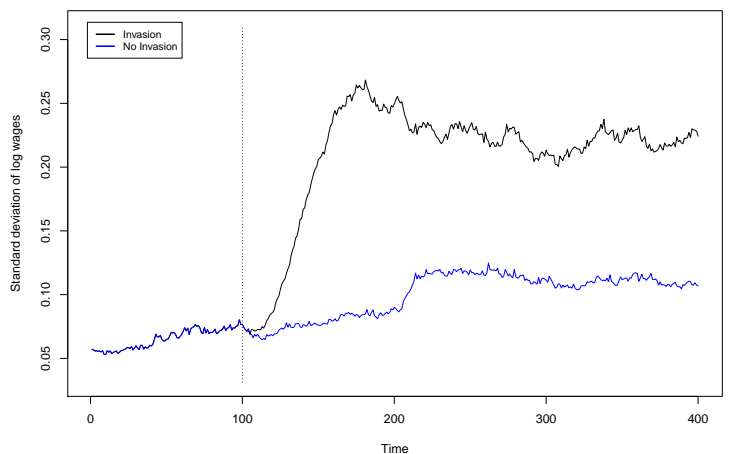

Lines: MC average for $100 \mathrm{MC}$ runs | Dotted vertical lines: regime change. 
Figure B.2: Comparison of FHK decomposition during the transition period in two scenarios.

(a) All firms

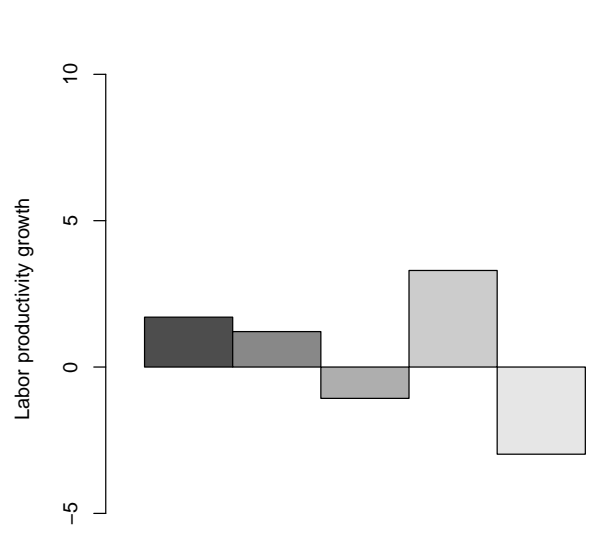

Invasion

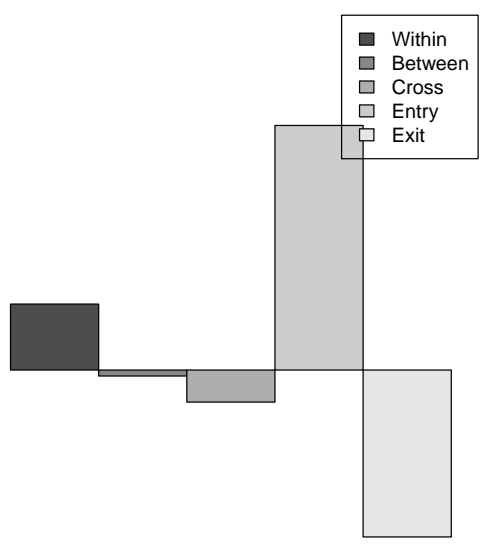

No Invasion

(b) Unionised firms
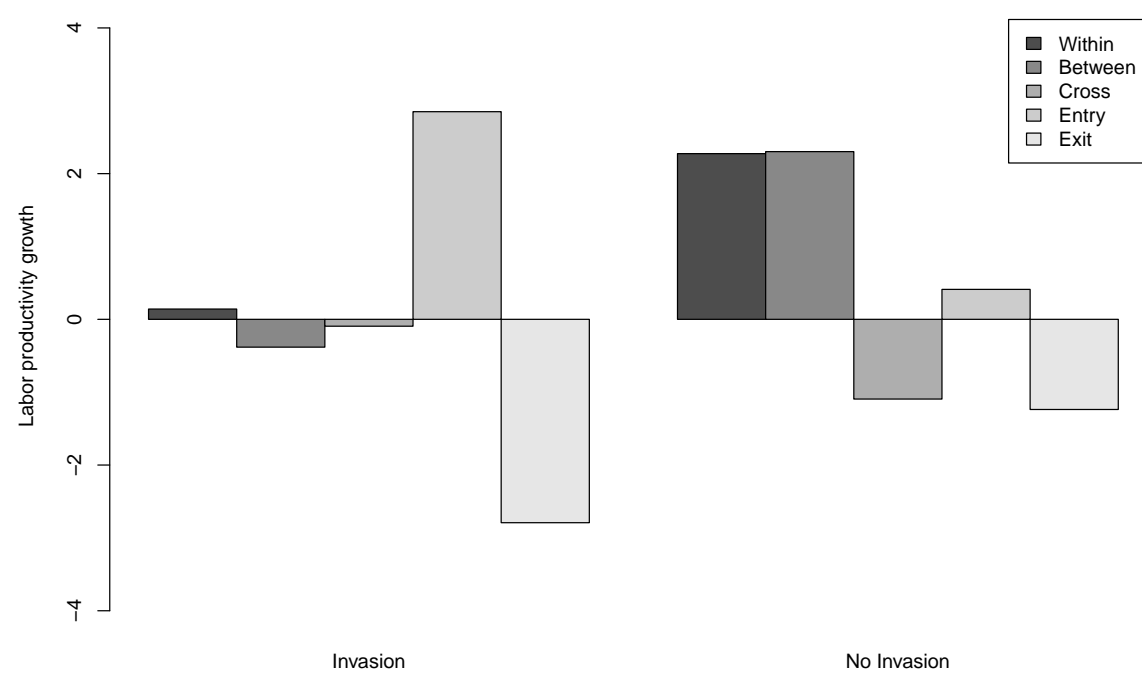

(c) Non-unionised firms
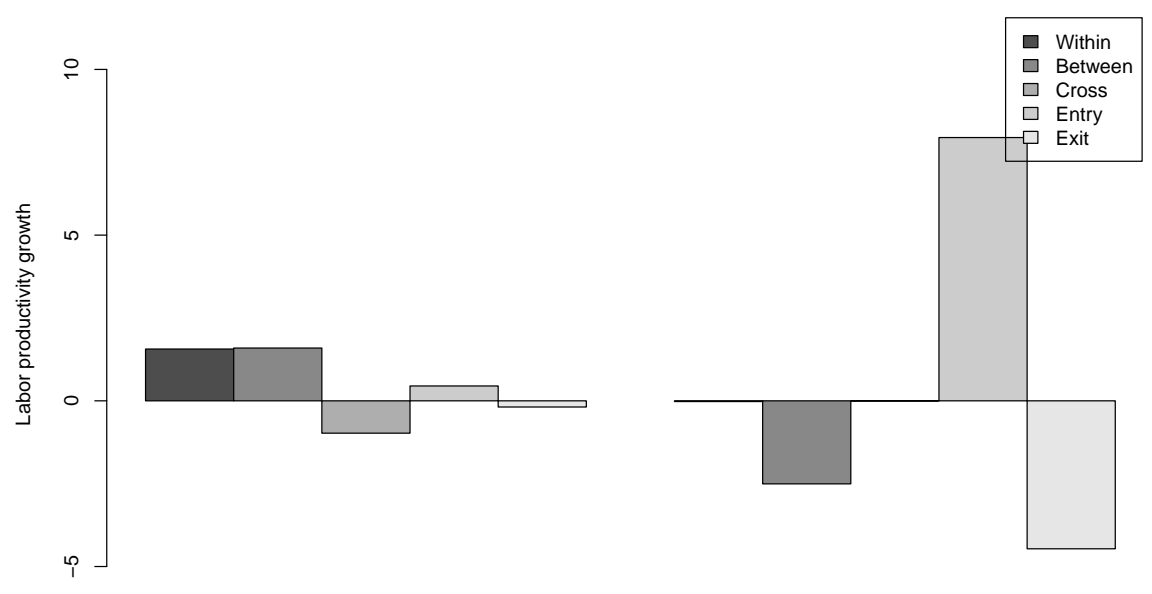

Invasion

No Invasion

Labour productivity growth moving averages for $100 \mathrm{MC}$ runs, 8-period window, period [170, 200]. 
Figure B.3: FHK decomposition based on different firm share measures in two scenarios.

(a) Decomposition based on firm employment shares (default)

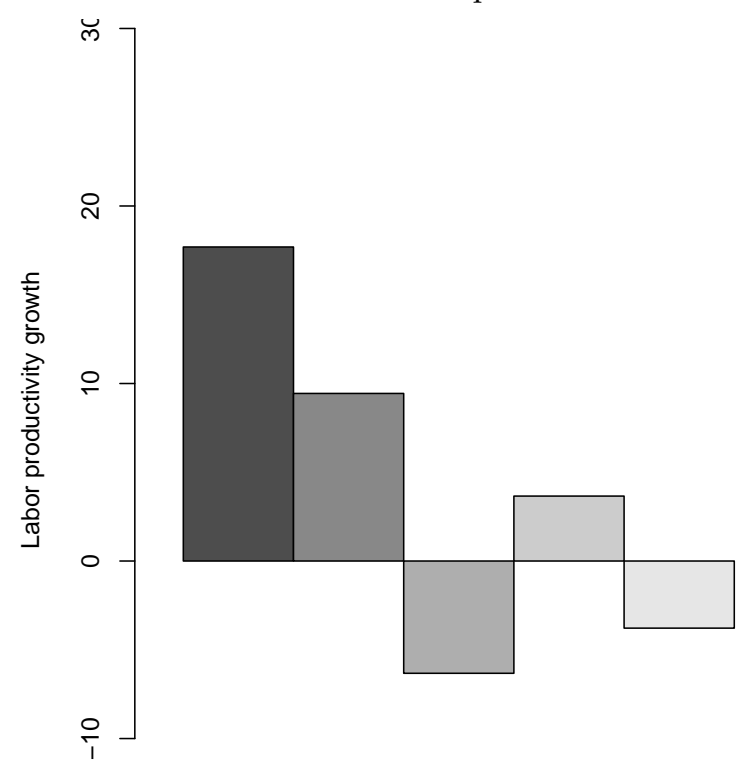

Invasion

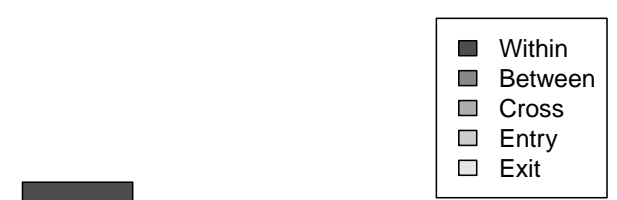

(b) Decomposition based on firm output shares

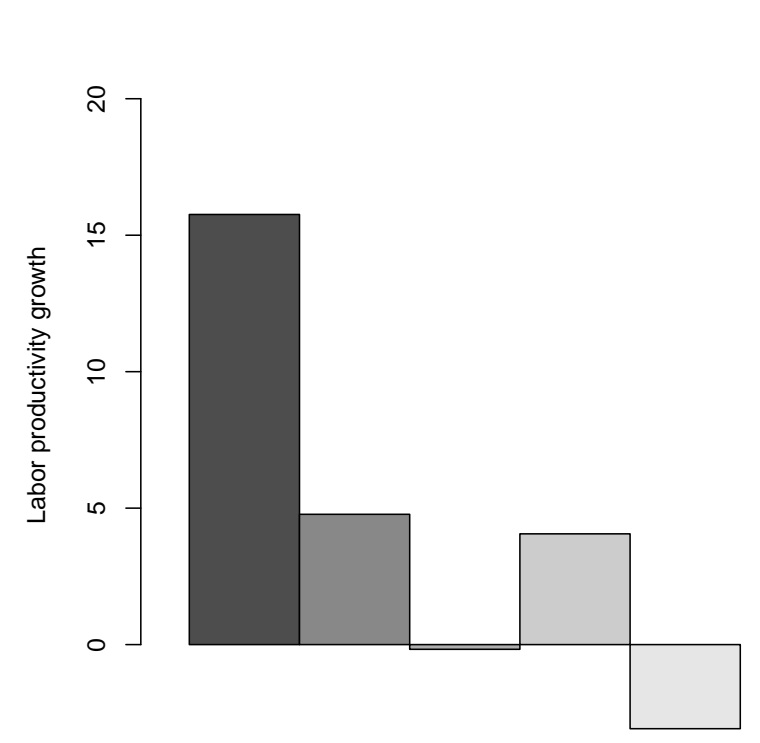

Invasion

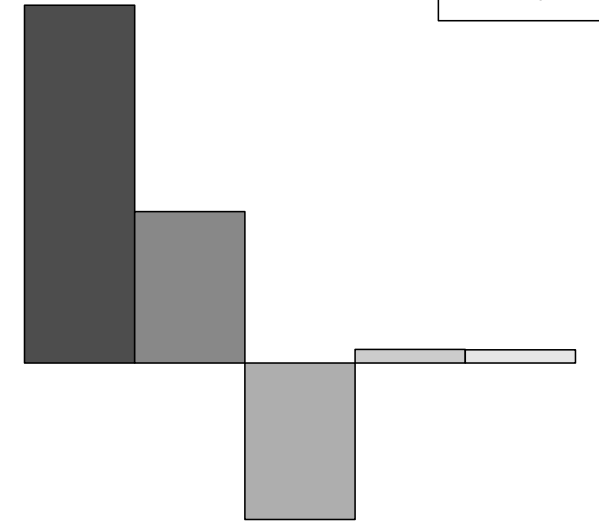

No Invasion . 


\section{Appendix C}

\section{Global sensitivity analysis}

The $\mathrm{K}+\mathrm{S}$ model is calibrated using the values presented in Table C.1 below (column VALUE) for the parameters and initial conditions. Global sensitivity analysis (SA) is performed across the entire parametric space, inside the closed region defined by Table C.1 (columns MIN. and MAX.), and the synthetic results are reported (columns $\mu^{*}$, DIRECT and INTERACTION) for the most sensitive among the tested output variables (results for the remaining variables can be requested to the authors). Two SA methodologies are employed, elementary effects (EE) and Sobol variance decomposition (SVD).

SA is performed for $t \in[200,400]$, i.e., after the transient period, on a set of output variables (the "metrics") relevant to the current discussion, namely the average overall productivity growth rate $(\Delta \bar{A})$ and standard deviation $\bar{A}^{s d}$, the mean joint market share of non-unionised firms $\left(\bar{f}^{n}\right)$, and the turbulence in the consumption-good market measured by the average number of exiting firms $\left(\bar{n}^{e x t, 2}\right) \cdot{ }^{17}$ All the model's parameters and initial conditions, their calibration values, as well as the key SA tests statistics, are detailed in the following.

EE analysis is summarized by the $\mu^{*}$ statistic in Table C.1, which is a measure of the direct absolute effects of each factor (parameter or initial condition) on the chosen output variable, being the parametric space rescaled to the $[0,1]$ interval on each dimension. The statistical significance of this statistic, the probability of not rejecting $H_{0}: \mu_{i}^{*}=0$ is also evaluated and indicated by the usual asterisk convention. The EE computation is performed directly over model samples from an optimized 10-trajectory one-at-a-time design of experiments (DoE). Each DoE sampling point is sampled three times, to compensate for stochastic components in the model.

The SVD analysis is reported in Table C.1 by two statistics: (DIRECT column) the decomposition of the direct influence of each factor on the variance of the tested output variable (adding up to 1), and (INTERACTION column) its indirect influence share, by interacting with other factors (non-linear/non-additive effects). The SVD analysis is performed using a Kriging meta-model fitted using samples from a near-orthogonal Latin hypercube DoE. Each DoE point is sampled 10 times.

The sensitivity analysis is performed on both scenarios, under successful invasion or not. However, the main results hold irrespective of the set-up. Out of the 67 parameters and initial conditions (the "factors") in this $\mathrm{K}+\mathrm{S}$ version, as a first step we apply the Morris elementary effects (EE) method. ${ }^{18}$ This is important because it allows identifying those factors which significantly affect the selected model metrics. The EE analysis (Table C.1) indicates that $\bar{n}^{e x t, 2}$ is the metric sensitive to the larger number of those factors (19) while $\Delta \bar{A}$ is the least sensitive, with 7 influential factors. ${ }^{19} \bar{A}^{\text {sd }}$ and $\bar{f}^{n}$ are in an intermediate

\footnotetext{
${ }^{17}$ Other relevant metrics, like the macro aggregates' growth rates, the inequality measures, and the industrial performance indicators were already evaluated in previous papers based on the labour-augmented $\mathrm{K}+\mathrm{S}$ model and are not be replicated here. The general results from these past analyses indicate a relatively small dependence of the model qualitative results on the chosen parametrization.

${ }^{18}$ Briefly, EE proposes both a specific design of experiments, to efficiently sample the parametric space under a multi-path, one-factor-at-a-time strategy, and a absolute importance statistic to evaluate direct and indirect (non-linear/non-additive) effects of the parameters on model results and their statistical significance (Morris, 1991, Saltelli et al., 2008).

${ }^{19}$ The selection criteria is to consider the top $80 \%$ EE contributors at $5 \%$ significance.
} 
situation with 14 and 12 influential factors, respectively. In total, 25 unique relevant factors were identified after discarding duplicates.

In order to quantify the effect of each of the relevant factors over the selected metrics, directly or in interaction with other factors, as a second step we perform a Sobol Variance Decomposition (SVD).$^{20}$ Because of the high computational cost to produce the SVD using the original simulation model, a simplified version of it - a meta-model - is estimated using the Kriging method and employed for the SVD. ${ }^{21}$ The meta-model is estimated by numerical maximum likelihood using a set of observations multi-sampled from the original model using a high-efficiency, nearly-orthogonal Latin hypercube design of experiments (Cioppa and Lucas, 2007).

The SVD results (Table C.1) indicate a smaller subset of 9 important factors for the chosen metrics. ${ }^{22}$ These factors, in overall order of importance, define (i) the intensity of the competition in the consumer-good market $(\chi)$, (ii) the tenure skill-accumulation rate for employed workers $\left(\tau_{T}\right)$, (iii) the work-life span before retirement $\left(T_{r}\right)$, (iv) the maximum technical advantage of an entrant firm $\left(x_{5}\right)$, (v) the shape of the technological opportunity space for entrants $\left(\alpha_{2}, \beta_{2}\right)$, (vi) the importance of unfilled demand for firm competitiveness $\left(\omega_{2}\right)$, (vii) the lower bound of the entrant-firm size distribution $\left(\bar{x}_{2}^{2}\right)$, and (viii) the initial number of firms in the consumer-good sector $\left(F_{0}^{2}\right)$. The equations and values related to each parameter are presented in Appendices A and C, respectively.

Overall, the impacts of all the tested factors in the SVD are relatively mild, and the differences between the two scenarios are small. ${ }^{23}$ Figure C.4 presents an exploration of the Kriging meta-model response surface for the two critical factors on each metric. The flat surfaces in Figures C.4(b), and C.4(c) indicate the linear interaction nature of the system response surfaces for the identified top-influence factors, $\tau_{T} / \alpha_{2}$, and $\chi / x_{5}$, respectively. Productivity growth $(\Delta \bar{A})$ shows the most rugged surface, indicating the intense presence on non-linearities in the interaction between the two factors, despite the small amplitude from minimum to maximum results (below 7\%). Additionally, just two factors, $\chi$ and $x_{5}$, account for more than $40 \%$ of the estimated meta-model effects on the market-dynamics metrics $\bar{f}^{n}$ and $\bar{n}^{e x t, 2}$. However, also for these two variables, the maximal amplitude of the effects is mild (both below 14\%). Therefore, for those three metrics, the model results are qualitatively robust to any parametric configuration.

The only metric for which factors influence is qualitatively relevant is the firmproductivity standard deviation $\left(\bar{A}^{s d}\right)$, as shown by Figure C.4(b). Firstly, it shows the strong impact of worker-skill accumulation, driven by parameter $\tau_{T}$, on the dispersion of the firm-level productivities. This hints at the significant consequences, in terms of firm

\footnotetext{
${ }^{20}$ The SVD is a variance-based, global SA method consisting in the decomposition of the chosen metrics variance into shares according to the contribution of the variances of the factors selected for analysis. This methodology deals better with non-linearities and non-additive interactions than EE or the traditional local SA methods. It allows to precisely disentangle both direct and interaction quantitative effects of the factors over the entire parametric space (Sobol, 1993, Saltelli et al., 2008).

${ }^{21}$ To summarize, the Kriging meta-model "mimics" the $\mathrm{K}+\mathrm{S}$ model using a simpler, mathematicallytractable approximation, fitted over a representative sample of the original model response surface. Kriging is a spatial interpolation method that under fairly general assumptions provides the best linear unbiased predictors for the response of complex, non-linear computer simulation models (Rasmussen and Williams, 2006, Salle and Yildizoglu, 2014).

${ }^{22}$ The selection criteria is to consider the top $80 \%$ SVD contributors.

${ }^{23}$ The response surfaces selected for Figure C.4 are the ones most affected in both scenarios by the indicated factors, which, in turn, are the two most relevant factors for each metric. Figures C.4(a), C.4(b), and C.4(d) are from the no-invasion case, while C.4(c) is from the invasion one.
} 
heterogeneity, of the interaction of learning and labour market processes in the model. Secondly, the importance of $\alpha_{2}$, or the minimum technological capabilities of entrant firms, in the classical "creative destruction" Schumpeterian sense. Indeed, this dispersion metric is very sensitive to changes of the two factors, additively, indicating the selected calibration point $\left(\tau_{T}=0.01, \alpha_{2}=2\right)$ is quite conservative in terms of the possibilities of the $\mathrm{K}+\mathrm{S}$ model in reproducing the empirical stylized fact of the sustained heterogeneity among firms. 


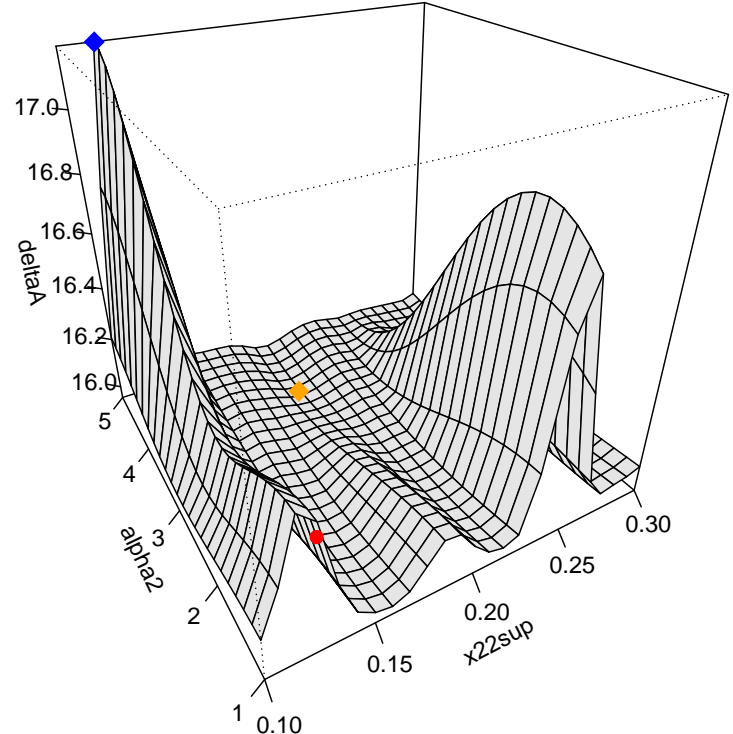

(a) Overall productivity growth rate $(\Delta \bar{A})$

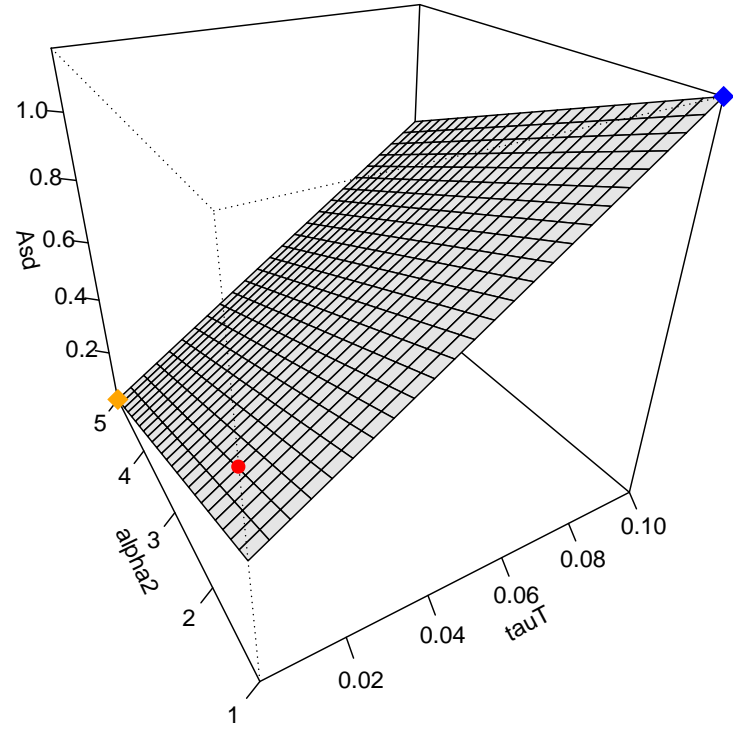

(b) Firm-productivity standard deviation $\left(\bar{A}^{s d}\right)$

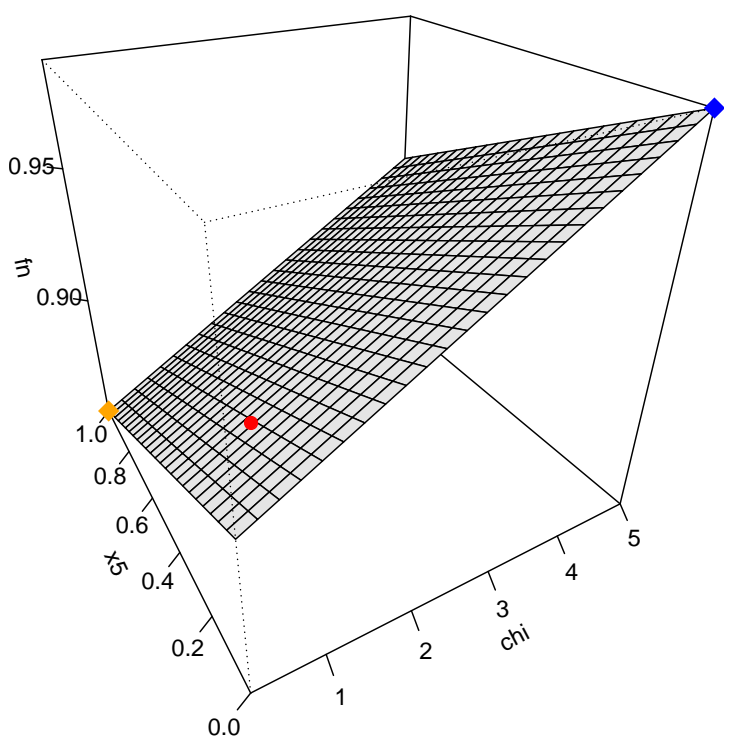

(c) Joint market share of non-unionised firms $\left(\bar{f}^{n}\right)$

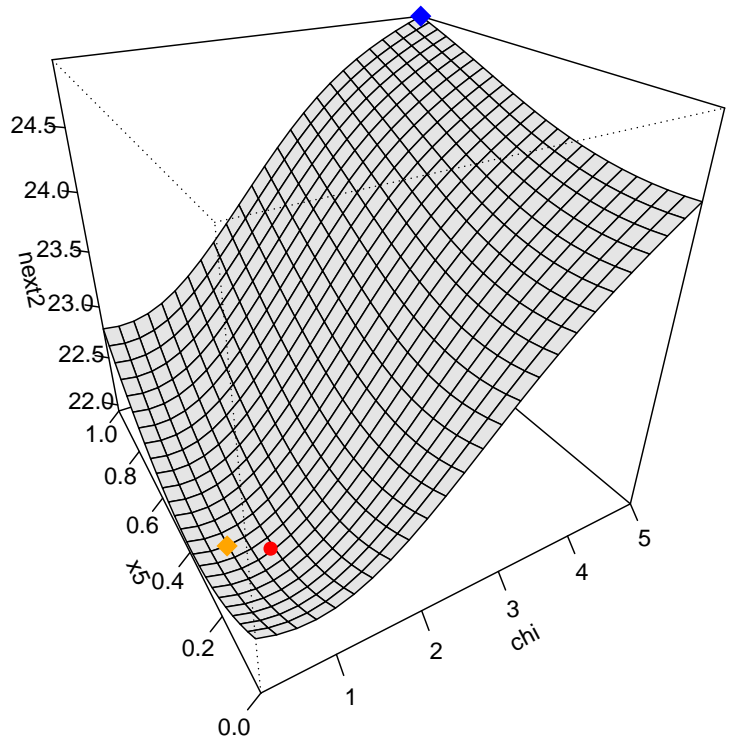

(d) Exiting consumption-good firms $\left(\bar{n}^{e x t, 2}\right)$

Figure C.4: Global sensitivity analysis response surfaces. Modelled using fitted Kriging metamodel.

Red dot: calibration settings I Markers: maximum (blue) and minimum (orange) predicted values. 
Table C.1: Model parameters and initial conditions, calibration values, minimum-maximum range for sensitivity analysis, elementary effects $\mu^{*}$ statistic ( $n=2040$ samples) and Sobol decomposition direct and interaction effects indexes ( $n=5120$ samples).

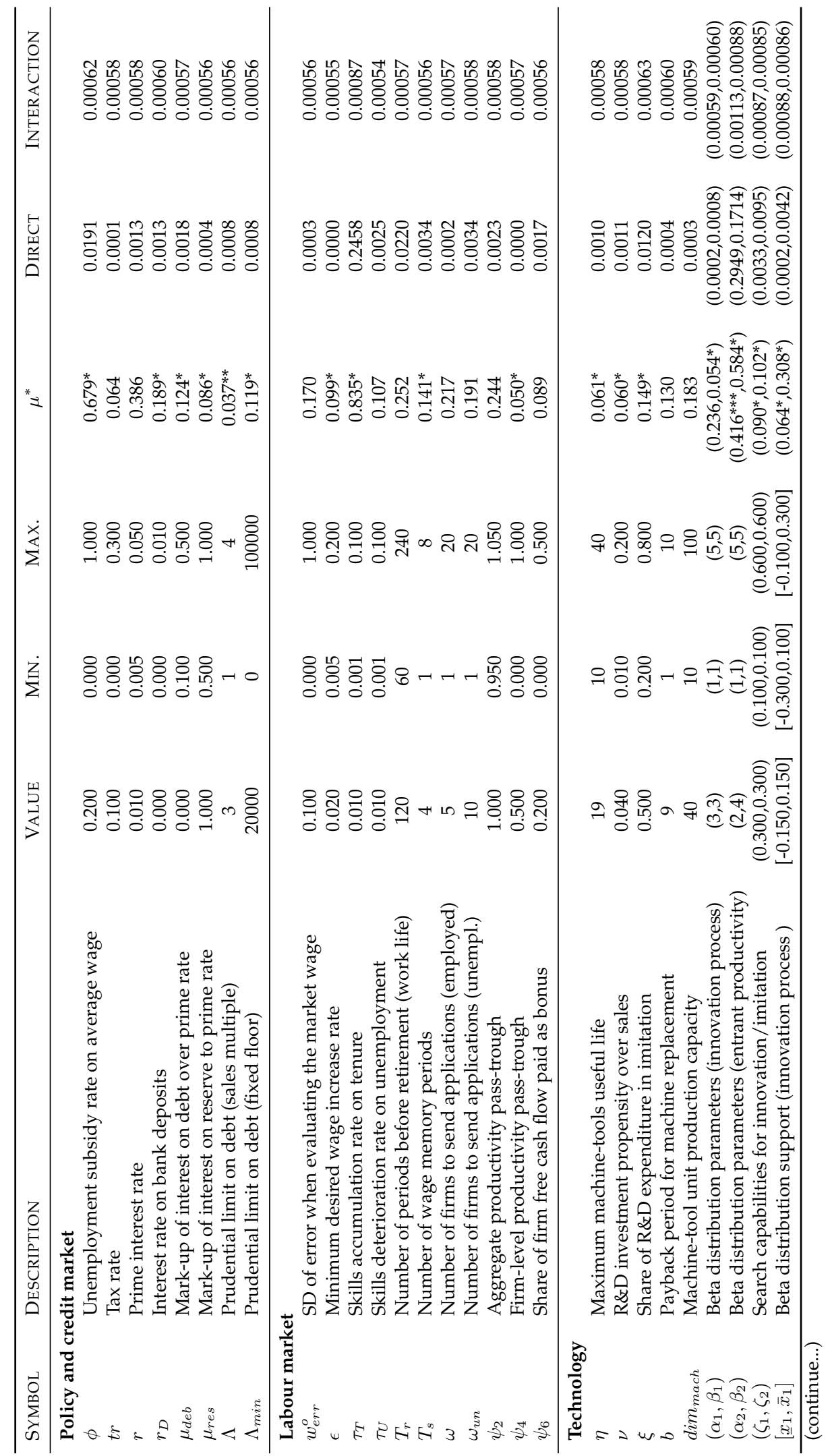

Baseline values for non-unionised firms. Sensitivity analysis statistics relative to the standard deviation of firm log productivity (the most sensitive variable). $\mu^{*}$ statistic estimated using factors rescaled to $[0,1] . \mu^{*}$ significance: ${ }^{* *} 0.1 \%\left|{ }^{* *} 1 \%\right| * 5 \%$ | (no asterisk) not significant at $5 \%$ level. 


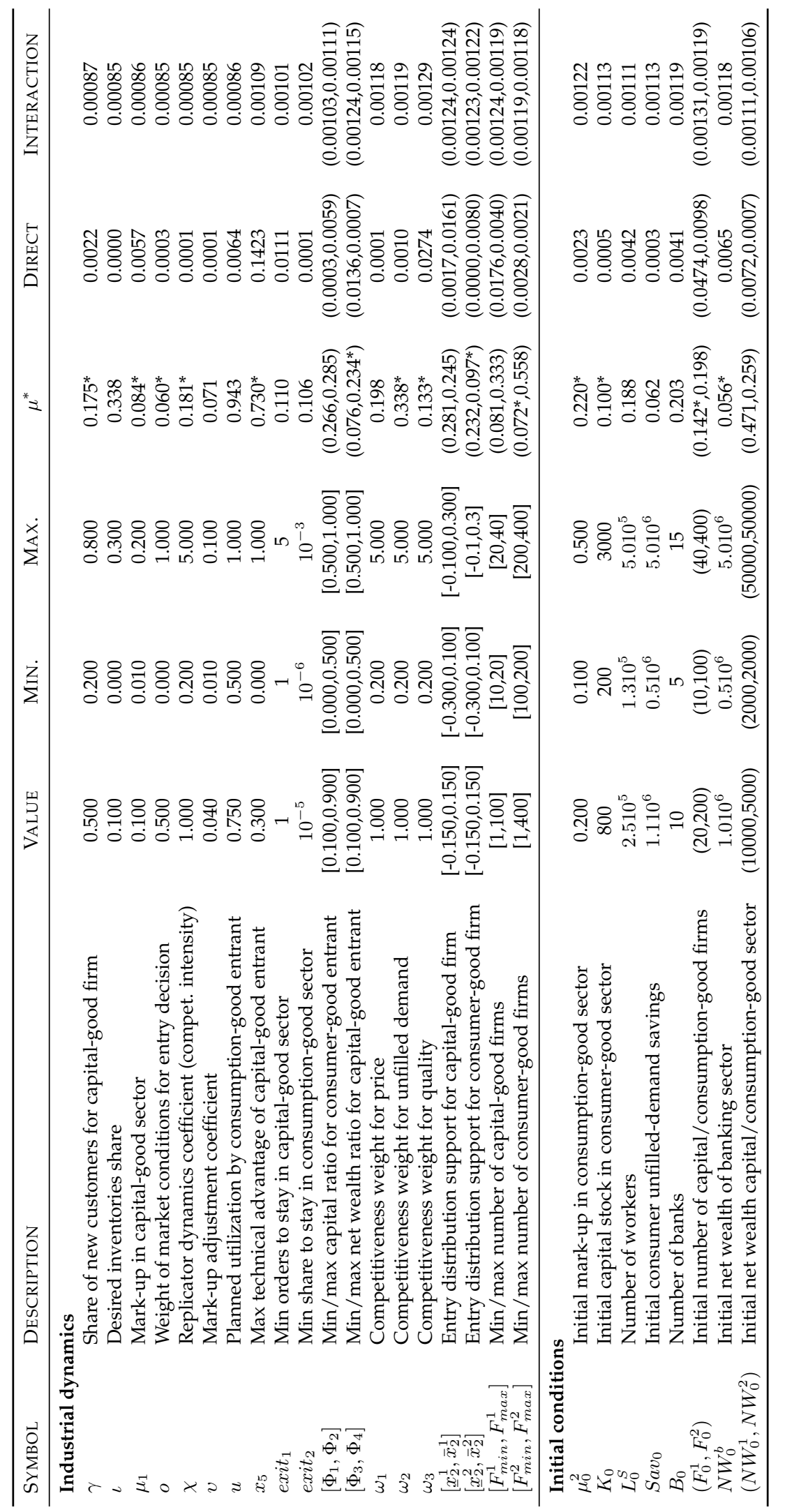

Baseline values for non-unionised firms. Sensitivity analysis statistics relative to the standard deviation of firm log productivity (the most sensitive variable). $\mu^{*}$ statistic estimated using factors rescaled to $[0,1] . \mu^{*}$ significance: ${ }^{* *} 0.1 \%|* * 1 \%| * 5 \%$ | (no asterisk) not significant at $5 \%$ level. 
Table C.2: Stock-and-flow consistency: transaction flow matrix. $\left.{ }^{*}\right)$ Government deficit/superavit is close to zero in the long run.

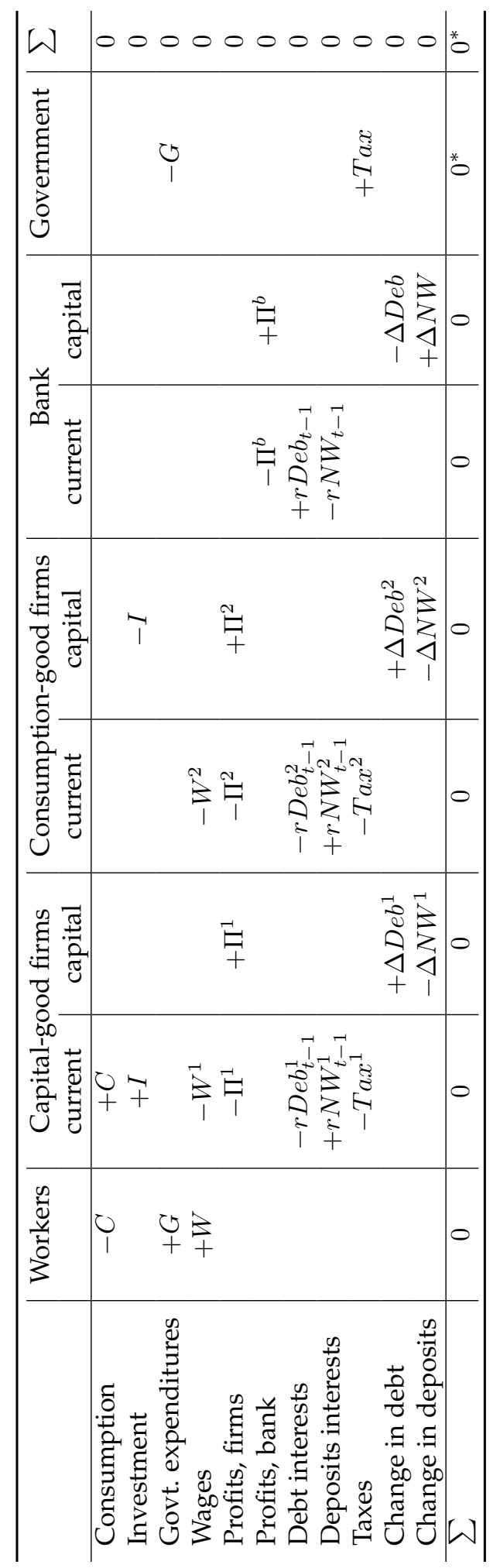

